Article

\title{
Hyperglycemia Induces Inflammatory Response of Human Macrophages to CD163-Mediated Scavenging of Hemoglobin-Haptoglobin Complexes
}

\author{
Laura Matuschik $^{1,2, *}$, Vladimir Riabov ${ }^{1}$, Christina Schmuttermaier $^{1}$, Tatyana Sevastyanova ${ }^{1}$, Christel Weiss $^{3}$, \\ Harald Klüter ${ }^{1,4}$ and Julia Kzhyshkowska ${ }^{1,4, *}$
}

1 Institute of Transfusion Medicine and Immunology, Mannheim Institute for Innate Immunoscience (MI3), Medical Faculty Mannheim, Heidelberg University, 68167 Mannheim, Germany;

Vladimir.Ryabov@medma.uni-heidelberg.de (V.R.); Christina.Schmuttermaier@medma.uni-heidelberg.de (C.S.);

Tatyana.Sevastyanova@medma.uni-heidelberg.de (T.S.); harald.klueter@medma.uni-heidelberg.de (H.K.)

2 Center of Surgery, Department of General and Visceral Surgery, Medical Center-University of Freiburg, Faculty of Medicine, 79106 Freiburg, Germany

3 Department of Medical Statistics and Biomathematics, Medical Faculty Mannheim, University of Heidelberg, 68167 Mannheim, Germany; Christel.Weiss@medma.uni-heidelberg.de

4 German Red Cross Blood Service Baden-Württemberg-Hessen, 68167 Mannheim, Germany

* Correspondence: laura.matuschik@uniklinik-freiburg.de (L.M.); Julia.Kzhyshkowska@medma.uni-heidelberg.de (J.K.)

Citation: Matuschik, L.; Riabov, V.; Schmuttermaier, C.; Sevastyanova, T.; Weiss, C.; Klüter, H.; Kzhyshkowska, J. Hyperglycemia Induces Inflammatory Response of Human Macrophages to CD163-Mediated Scavenging of Hemoglobin-Haptoglobin Complexes. Int. J. Mol. Sci. 2022, 23, 1385 https://doi.org/10.3390/ ijms23031385

Academic Editor:

David Della-Morte

Received: 31 December 2021

Accepted: 19 January 2022

Published: 26 January 2022

Publisher's Note: MDPI stays neutral with regard to jurisdictional claims in published maps and institutional affiliations.

Copyright: (C) 2022 by the authors. Licensee MDPI, Basel, Switzerland. This article is an open access article distributed under the terms and conditions of the Creative Commons Attribution (CC BY) license (https:// creativecommons.org/licenses/by/ $4.0 /)$.

\begin{abstract}
Hyperglycemia, a hallmark of diabetes, can induce inflammatory programming of macrophages. The macrophage scavenger receptor CD163 internalizes and degrades hemoglobinhaptoglobin ( $\mathrm{Hb}-\mathrm{Hp})$ complexes built due to intravascular hemolysis. Clinical studies have demonstrated a correlation between impaired scavenging of $\mathrm{Hb}-\mathrm{Hp}$ complexes via CD163 and diabetic vascular complications. Our aim was to identify whether hyperglycemia is able to amplify inflammation via $\mathrm{Hb}-\mathrm{Hp}$ complex interactions with the immune system. M(IFN $\gamma), \mathrm{M}(\mathrm{IL}-4)$, and control M0 macrophages were differentiated out of primary human monocytes in normo- $(5 \mathrm{mM})$ and hyperglycemic $(25 \mathrm{mM})$ conditions. CD163 gene expression was decreased 5.53 times in M(IFN $\gamma)$ with a further decrease of 1.99 times in hyperglycemia. Hyperglycemia suppressed CD163 surface expression in M(IFN $\gamma$ ) (1.43 times). Flow cytometry demonstrated no impairment of $\mathrm{Hb}-\mathrm{Hp}$ uptake in hyperglycemia. However, hyperglycemia induced an inflammatory response of $\mathrm{M}(\mathrm{IFN} \gamma)$ to $\mathrm{Hb}-\mathrm{Hp} 1-1$ and $\mathrm{Hb}-\mathrm{Hp} 2-2$ uptake with different dynamics. Hb-Hp1-1 uptake stimulated IL-6 release (3.03 times) after $6 \mathrm{~h}$ but suppressed secretion (5.78 times) after $24 \mathrm{~h}$. Contrarily, Hb-Hp2-2 uptake did not affect IL-6 release after $6 \mathrm{~h}$ but increased secretion after $24 \mathrm{~h}$ (3.06 times). Our data show that hyperglycemia induces an inflammatory response of innate immune cells to $\mathrm{Hb}-\mathrm{Hp} 1-$ 1 and $\mathrm{Hb}-\mathrm{Hp} 2-2$ uptake, converting the silent $\mathrm{Hb}-\mathrm{Hp}$ complex clearance that prevents vascular damage into an inflammatory process, hereby increasing the susceptibility of diabetic patients to vascular complications.
\end{abstract}

Keywords: diabetes mellitus; hyperglycemia; macrophages; inflammation; CD163; scavenger receptor; hemoglobin-haptoglobin complexes

\section{Introduction}

Diabetes mellitus is a heterogeneous group of metabolic disorders sharing the common ground of chronic hyperglycemia that induces micro- and macrovascular complications [1,2]. Large clinical trials, i.e., the Diabetes Control and Complications Trial (DCCT) and the United Kingdom Prospective Diabetes Study (UKPDS), found that the duration and degree of hyperglycemia correlates with the extent of microvascular complications [3,4]. Hyperglycemia can cause vascular complications by direct and indirect mechanisms, by the 
activation of detrimental inflammatory pathways in endothelial cells or by activation of immune cells, primarily of myeloid origin [5-8]. It was suggested that subclinical chronic systemic inflammation creates conditions for vascular damage [9-11]. Chronic inflammation is characterized by only moderate elevation of inflammatory cytokines, e.g., TNF $\alpha$, IL-1 $\beta$, and IL-6, induced by exogenous or endogenous factors [12]. The major source of inflammatory cytokines in chronic inflammation are macrophages. We have demonstrated previously that human macrophages respond to hyperglycemia by elevated production of predominantly proinflammatory cytokines [6,13]. Hyperglycemia can induce an inflammatory program in innate immune cells on the epigenetic level, as we showed for the enhanced presence of activating histone marks on the promoters of S100A9 and S100A12 genes, responsible for vascular inflammation in diabetes $[7,14-16]$. However, macrophages control inflammation not only by the release of proinflammatory factors, but also by their complex scavenging activity, which can be silent and tolerogenic, or can provoke additional inflammation. The effect of hyperglycemia on this essential function of monocytes and macrophages is unexplored.

CD163 is a scavenger receptor expressed on circulating monocytes and on tissue macrophages in different pathologies [17-20]. CD163 controls inflammation by the internalization and degradation of hemoglobin-haptoglobin ( $\mathrm{Hb}-\mathrm{Hp})$ complexes [21]. Expression of CD163 is controlled by pro- and anti-inflammatory factors, where anti-inflammatory agents, such as glucocorticoids and IL-10, stimulate CD163 expression, and proinflammatory cytokines, such as IFN $\gamma$ and $\mathrm{TNF} \alpha$, suppress CD163 expression [22-26]. The anti-inflammatory cytokine IL-4 had no effect on CD163 protein expression [23,27].

The most comprehensively characterized function of CD163 is its homeostatic role in the scavenging of $\mathrm{Hb}-\mathrm{Hp}$ complexes formed as a result of intravascular hemolysis. This mechanism physiologically occurs for 10-20\% of erythrocytes and increases considerably in pathological conditions, e.g., hemoglobinopathies or inflammation $[21,28]$. The formation of $\mathrm{Hb}-\mathrm{Hp}$ complexes protects the endothelium and kidneys from the toxicity of free hemoglobin by preventing renal deposition of free hemoglobin resulting in parenchymal and vascular damage $[28,29]$.

$\mathrm{Hb}-\mathrm{Hp}$ complexes bind with high affinity to membrane-bound CD163 of both circulating monocytes and tissue macrophages, leading to their internalization and degradation via the cytoprotective and anti-inflammatory heme oxygenase-1 [21,30,31]. This anti-inflammatory capacity is decreased in diabetes mellitus, as CD163 mRNA expression in peripheral blood mononuclear cells (PBMCs) is significantly suppressed in newly diagnosed diabetic patients [32]. Moreover, the percentage of macrophages in atherosclerotic plaques and PBMC expressing CD163 was significantly reduced in diabetic patients compared to non-diabetic individuals $[28,33]$. Haptoglobin, the protein binding to free extracorpuscular hemoglobin, exists in two known allelic variants: $H p 1$ and $H p 2$, leading to three possible phenotypes: Hp1-1, Hp1-2, and Hp2-2 [34]. Haptoglobin serum levels differ considerably from $0.3-3.0 \mathrm{mg} / \mathrm{mL}$ between healthy individuals but stay reasonably constant for one individual, and are saturated when $500-1500 \mathrm{mg} / \mathrm{L}$ free hemoglobin is present in serum [34,35]. During inflammation, haptoglobin, which is a hepatocyte-produced acute-phase protein, is induced 2-5-fold by the acute-phase mediators IL-1 and IL-6 and can be released locally from storage granules by active neutrophils [36,37]. The clearance and antioxidant capacity of individuals expressing Hp1-1 has been observed to be superior to in Hp2-2 individuals [38,39]. Longitudinal prospective studies have demonstrated that the Hp2-2 phenotype is an independent risk factor for the development of cardiovascular disease and increased susceptibility to vascular complications in diabetic individuals in comparison with the homozygous Hp1-1 variant [33,34,40]. As a possible mechanism for the proneness to vascular complications, it has been demonstrated that CD163 is downregulated in macrophages in atherosclerotic plaques of diabetic patients with the Hp2-2 genotype, indicating a compromised hemoglobin clearing capability [33]. 
Although clinical studies found a correlation between the impaired scavenging of $\mathrm{Hb}-\mathrm{Hp}$ complexes in diabetes mellitus, the effect of hyperglycemia on the expression and scavenging activity of CD163 in primary human macrophages has not been studied to date.

We hypothesized that hyperglycemia might have a novel mechanism of amplifying inflammation via $\mathrm{Hb}-\mathrm{Hp}$ complex interactions with the immune system, as hyperglycemia has already been identified as a direct driver of inflammatory cytokine release in monocytes and macrophages. In this study, we focused on the essential monocyte/macrophage clearance functions required to eliminate $\mathrm{Hb}-\mathrm{Hp}$ complexes. We specifically analyzed the differences between Hp1-1 and Hp2-2 effects in hyperglycemic conditions in terms of the dynamics and spectrum of this inflammatory response relevant to the clinically observed susceptibility of diabetic patients expressing the Hp2-2 variant to the development of vascular complications.

\section{Results}

2.1. IFN $\gamma$ and IL-4 Suppress CD163 Expression in Macrophages, and Hyperglycemia Enhances the IFN Effect

Human primary monocyte-derived macrophages were differentiated into homeostatic (M(Control)) M0 macrophages, inflammatory (M(IFN $\gamma)$ ), and healing (M(IL-4)) macrophages in normal and hyperglycemic conditions, and the gene expression of CD163 was quantified by RT-PCR (Figure 1A). Hyperglycemia did not affect CD163 expression in M0. IFN $\gamma$ had a statistically significant inhibitory effect on CD163 expression compared to M0 macrophages (5.53 times decrease, $p$-value < 0.0001) (Figure 1A). Hyperglycemia enhanced this effect 1.99 times; however, statistical significance was not reached due to individual donor responses (Figure 1A, individual donors shown in Supplementary Figure S4). The suppressing effect of IL-4 on CD163 gene expression was very strong (fold change $4.76, p$-value $<0.0001$ ) but did not reach the suppressive level of IFN $\gamma$ (Figure 1A). Hyperglycemia had almost no effect on the IL-4-mediated suppression of CD163 gene expression. Flow cytometry quantification of CD163 surface expression demonstrated, similarly to gene expression, a strong suppressive effect of IFN $\gamma$ compared to the control conditions (3.4 times, $p$-value < 0.01) (Figure 1B). Hyperglycemia had an additional statistically significant effect on the suppression of CD163 surface expression in M(IFN $\gamma$ ) (fold change $1.43, p$-value < 0.01) (Figure 1B, data for individual donors are shown in Supplementary Figure S5). However, in contrast to gene expression levels, in M(IL-4), surface expression levels of CD163 did not change compared to M(Control), suggesting that an additional mechanism in healing macrophages can support sufficient levels of surface CD163 to ensure control of inflammatory responses.

\subsection{CD163-Mediated Internalization of Hb-Hp Complexes Is Efficient in NG and HG Conditions in $M 0$ and $M(I L-4)$ Macrophages}

To identify the functional consequences of the observed regulation of CD163, we examined the effect of hyperglycemia on the scavenging function of CD163. Therefore, we quantitatively evaluated the uptake of fluorescently labeled hemoglobin-haptoglobin complexes (Hb-Hp1-1 complexes and $\mathrm{Hb}-\mathrm{Hp} 2-2$ complexes) by differentially stimulated macrophages via flow cytometry. M0 and M(IL-4) efficiently internalized both Hb-Hp1-1 (M(IL-4) compared to M(IFN $\gamma$ ) (fold change 3.7, $p$-value $<0.01$, Figure 2A) and $\mathrm{Hb}-\mathrm{Hp} 2-2$ complexes (M(IL-4) compared to M(IFN $\gamma$ ) (fold change 4.7, $p$-value $<0.01$, Figure $2 \mathrm{~B}$ ) in normoglycemia. In hyperglycemic conditions, too, uptake of $\mathrm{Hb}-\mathrm{Hp} 1-1$ and $\mathrm{Hb}-\mathrm{Hp} 2-2$ was significantly impaired in M(IFN $\gamma$ ) compared to M0 and M(IL-4) (Hb-Hp1-1: M(IL-4) compared to M(IFN $\gamma$ ) (fold change 3.6, $p$-value < 0.001, Figure 2A) and Hb-Hp2-2: M(IL-4) compared to $\mathrm{M}(\mathrm{IFN} \gamma)$ (fold change 4.2, $p$-value $<0.001$, Figure $2 \mathrm{~B}$ ), which correlated with significantly suppressed surface levels of CD163 in M(IFN $\gamma$ ) (Figure 1B). There was no difference in the endocytosis efficiency of $\mathrm{Hb}-\mathrm{Hp} 1-1$ and $\mathrm{Hb}-\mathrm{Hp} 2-2$ in hyperglycemic conditions. 


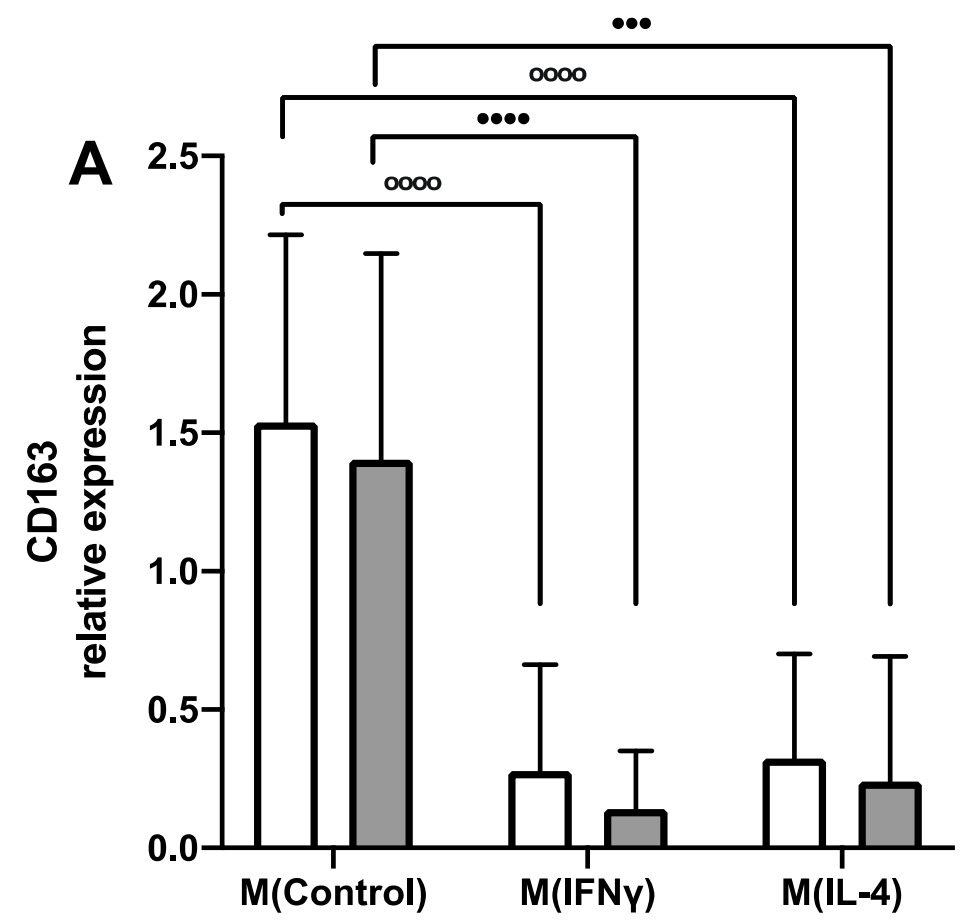

CD163 mRNA

expression

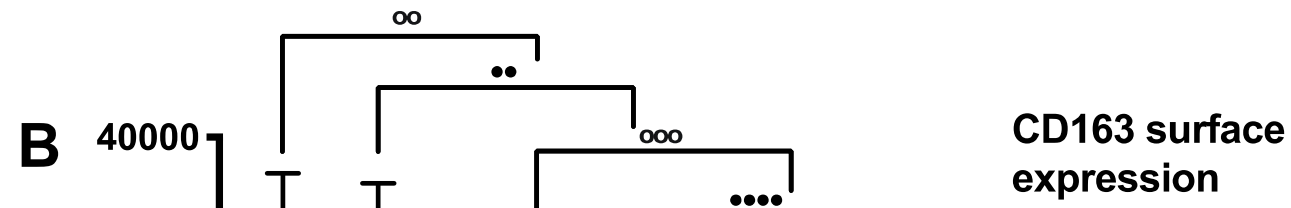

Figure 1. RT-PCR and flow cytometry analysis of CD163 expression in differentially stimulated macrophages. Monocyte-derived macrophages were cultured for 6 days in normal-glucose $(5 \mathrm{mM}$, NG) and high-glucose ( $25 \mathrm{mM}, \mathrm{HG})$ conditions and stimulated with either IFN $\gamma$ or IL-4 or without further cytokines (M(Control)). (A): mRNA expression was measured by RT-PCR. Graph depicts the mean values of 8 donors \pm SD. For statistical analysis, the Wilcoxon matched-pairs rank test was used. (B): Fluorescence intensity was measured by flow cytometry. Graph depicts the mean values of 6 donors \pm SD. For statistical analysis, a paired $t$ test was used. * denotes statistical significance between normal- and high-glucose conditions $\left({ }^{* *} p<0.01\right){ }^{\circ}$ denotes statistical significance between different cytokine stimulations in NG conditions $\left({ }^{\circ} p<0.01,{ }^{\circ} p \circ p<0.001,{ }^{\circ 00} p<0.0001\right)$. $\bullet$ denotes statistical significance between different cytokine stimulations in HG conditions $(\bullet \bullet p<0.01$, $\bullet p<0.001, \bullet \bullet \bullet<0.0001$ ). 

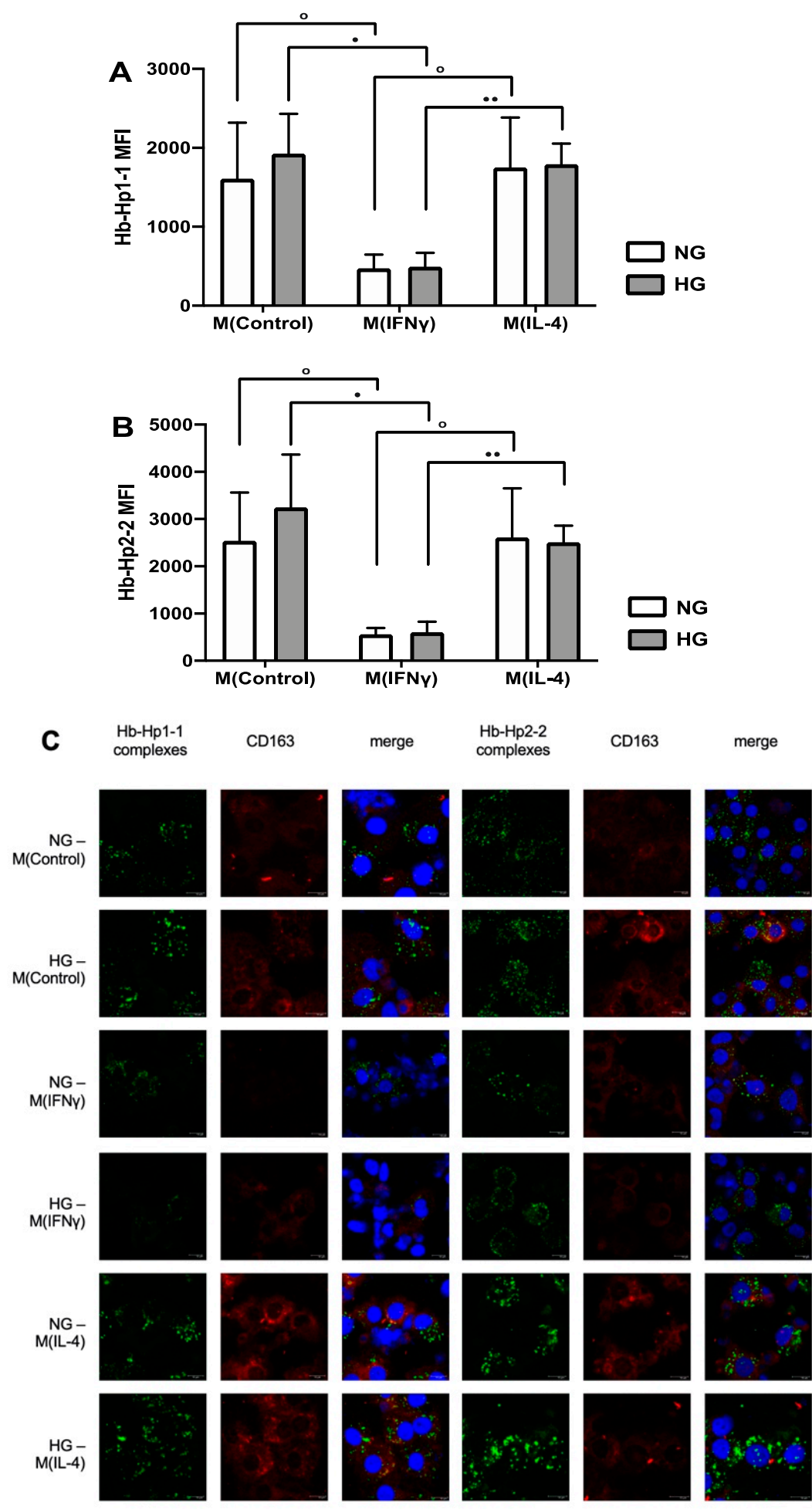

Figure 2. Endocytosis of Alexa Fluor ${ }^{\circledR}$ 488-labeled Hb-Hp1-1-/Hp2-2-complexes in normoglycemic and hyperglycemic conditions in differentially activated macrophages. Endocytosis was performed on day 6 of macrophage differentiation (control, IFN $\gamma$-stimulated, and IL-4-stimulated) in normal (5 mM, NG) and high (25 mM, HG) glucose conditions. Macrophages were incubated with Hb-Hp1-1 or $\mathrm{Hb}-\mathrm{Hp} 2-2$ complexes for $30 \mathrm{~min}$. (A): flow cytometry analysis after stimulation with Hb-Hp1-1 complexes; (B): flow cytometry analysis after stimulation with $\mathrm{Hb}-\mathrm{Hp} 2-2$ complexes. Mean fluorescence intensity (MFI) values shown on the graphs are after subtraction of 'no ligand' controls. Graphs depict the mean fluorescence intensity values of 5 individual donors \pm SD. For statistical analysis, a 
paired $t$ test was used. ${ }^{\circ}$ denotes statistical significance between different cytokine stimulations in NG conditions $\left({ }^{\circ} p<0.05\right)$. denotes statistical significance between different cytokine stimulations in HG conditions $(\bullet p<0.05, \bullet \bullet<0.01)$. (C): Confocal microscopy analysis. Alexa Fluor ${ }^{\circledR} 488$-labeled $\mathrm{Hb}-\mathrm{Hp} 1-1-/ \mathrm{Hp} 2-2-c o m p l e x e s$ are visualized in green. CD163 was detected with a goat polyclonal anti-human CD163 antibody and Cy3-labeled donkey anti-goat secondary antibody (shown in red). Nuclei were stained with DRAQ5 (shown in blue). Yellow-orange color indicates co-localization of $\mathrm{Hb}-\mathrm{Hp}$ complexes and CD163. The scale bar indicates $10 \mu \mathrm{m}$.

The internalization of $\mathrm{Hb}-\mathrm{Hp} 1-1$ and $\mathrm{Hb}-\mathrm{Hp} 2-2$ complexes was visualized by confocal microscopy and confirmed efficient endocytosis of complexes in M0 and M(IL-4), and only residual endocytosis in $\mathrm{M}(\mathrm{IFN} \gamma$ ) (Figure $2 \mathrm{C}$ ). The endocytosis of $\mathrm{Hb}-\mathrm{Hp} 1-1$ and $\mathrm{Hb}-\mathrm{Hp} 2-2$ in hyperglycemic conditions was as efficient as in normoglycemic conditions. Even though the haptoglobin variants Hp1-1 and Hp2-2 differ considerably in their molecular structure [34], we observed the same uptake pattern for both complexes. The uptake efficiency was dependent on macrophage polarization, which defines the levels of CD163 surface exposure. There was no functional impairment of endocytosis of $\mathrm{Hb}-\mathrm{Hp} 1-1$ and $\mathrm{Hb}-\mathrm{Hp} 2-2$ via CD163 in hyperglycemia.

2.3. Hyperglycemia Enhances the Release of Inflammatory Cytokines in Response to Scavenging of Hemoglobin-Haptoglobin Complexes via CD163 in M(IFN $\gamma)$

Next, we analyzed whether the uptake of $\mathrm{Hb}-\mathrm{Hp}$ complexes can affect inflammatory activation of macrophages. $\mathrm{CD} 14^{+}$monocytes of healthy donors were differentiated for 6 days in a serum-free medium complemented with IFN $\gamma$ in normal $(5 \mathrm{mM}, \mathrm{NG})$ and high (25 mM, HG) glucose conditions. On day 6, macrophages were stimulated with $\mathrm{Hb}-\mathrm{Hp} 1-1$ complexes or Hb-Hp2-2 complexes at concentrations of 1 and $10 \mu \mathrm{g} / \mathrm{mL}$, as the haptoglobin level varies individually from $0.3-3 \mathrm{mg} / \mathrm{mL}$ and, as an acute-phase protein, its physiological plasma levels increase 2-5-fold in inflammation [34,36,37,41]. We selected a set of inflammatory cytokines $(\mathrm{TNF} \alpha, \mathrm{IL}-1 \beta, \mathrm{IL}-6, \mathrm{IL}-8$, and IL- 1 receptor antagonist (IL-1RA)) as a read-out. The concentration of these cytokines was identified 6 and $24 \mathrm{~h}$ after stimulation with $\mathrm{Hb}-\mathrm{Hp} 1-1$ or $\mathrm{Hb}-\mathrm{Hp} 2-2$ complexes (experimental design: Figure 3A).

The secretion of our read-out cytokines tended to be enhanced in hyperglycemic conditions in the absence and also in the presence (after 6 and 24h) of Hb-Hp complex stimulation (Figure 3B-F).

The release of the acute-phase inflammatory cytokine $\mathrm{TNF} \alpha$ was stimulated by $\mathrm{Hb}-\mathrm{Hp} 1-1$ complexes after $6 \mathrm{~h}$ in NG, with this effect being significantly enhanced by hyperglycemia (Figure 3B). The increase in hyperglycemic conditions was similar for $\mathrm{Hb}-\mathrm{Hp} 1-1$ complex concentrations of 1 (1.57 times, $p$-value $<0.01)$ and $10 \mu \mathrm{g} / \mathrm{mL}(1.61$ times, $p$-value $<0.01)$. However, $24 \mathrm{~h}$ after the stimulation with $\mathrm{Hb}-\mathrm{Hp} 1-1$ complexes, suppression of TNF $\alpha$ secretion was detected in both normo- and hyperglycemic conditions, with a statistically significant effect in hyperglycemia $24 \mathrm{~h}$ after stimulation with $10 \mu \mathrm{g} / \mathrm{mL} \mathrm{Hb}-\mathrm{Hp} 1-1$ complexes (1.29 times suppression, $p$-value $<0.05$ ). The stimulation with Hb-Hp2-2 complexes per se had no statistically significant effect on $\mathrm{TNF} \alpha$ release compared to nonstimulated macrophages (Figure 3B). However, hyperglycemia significantly enhanced $\mathrm{TNF} \alpha$ release $6 \mathrm{~h}$ after stimulation with Hb-Hp2-2 complexes $(1 \mu \mathrm{g} / \mathrm{mL}: 1.65$ times, $p$-value $<0.01 ; 10 \mu \mathrm{g} / \mathrm{mL}$ : 1.61 times, $p$-value < 0.01) (Figure 3B). A statistically significant increase in TNF $\alpha$ secretion could only be detected $6 \mathrm{~h}$ after the stimulation with $\mathrm{Hb}-\mathrm{Hp}$ complexes in hyperglycemia, regardless of the present haptoglobin variant. 


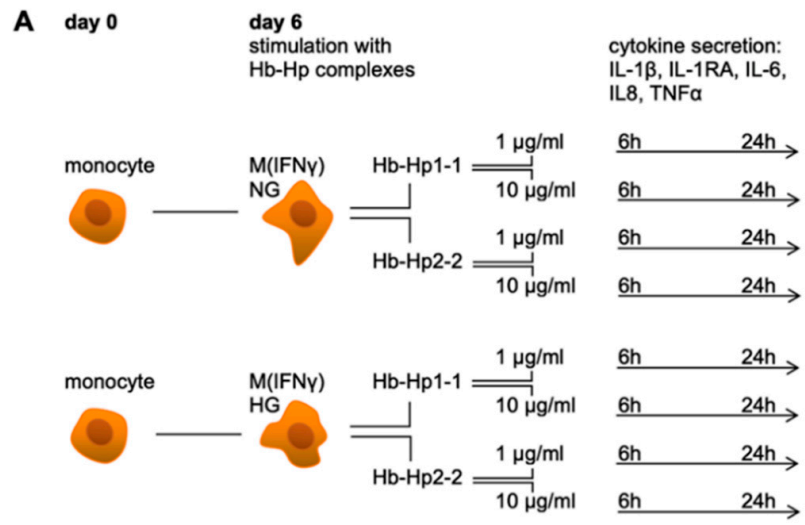

$6 h$
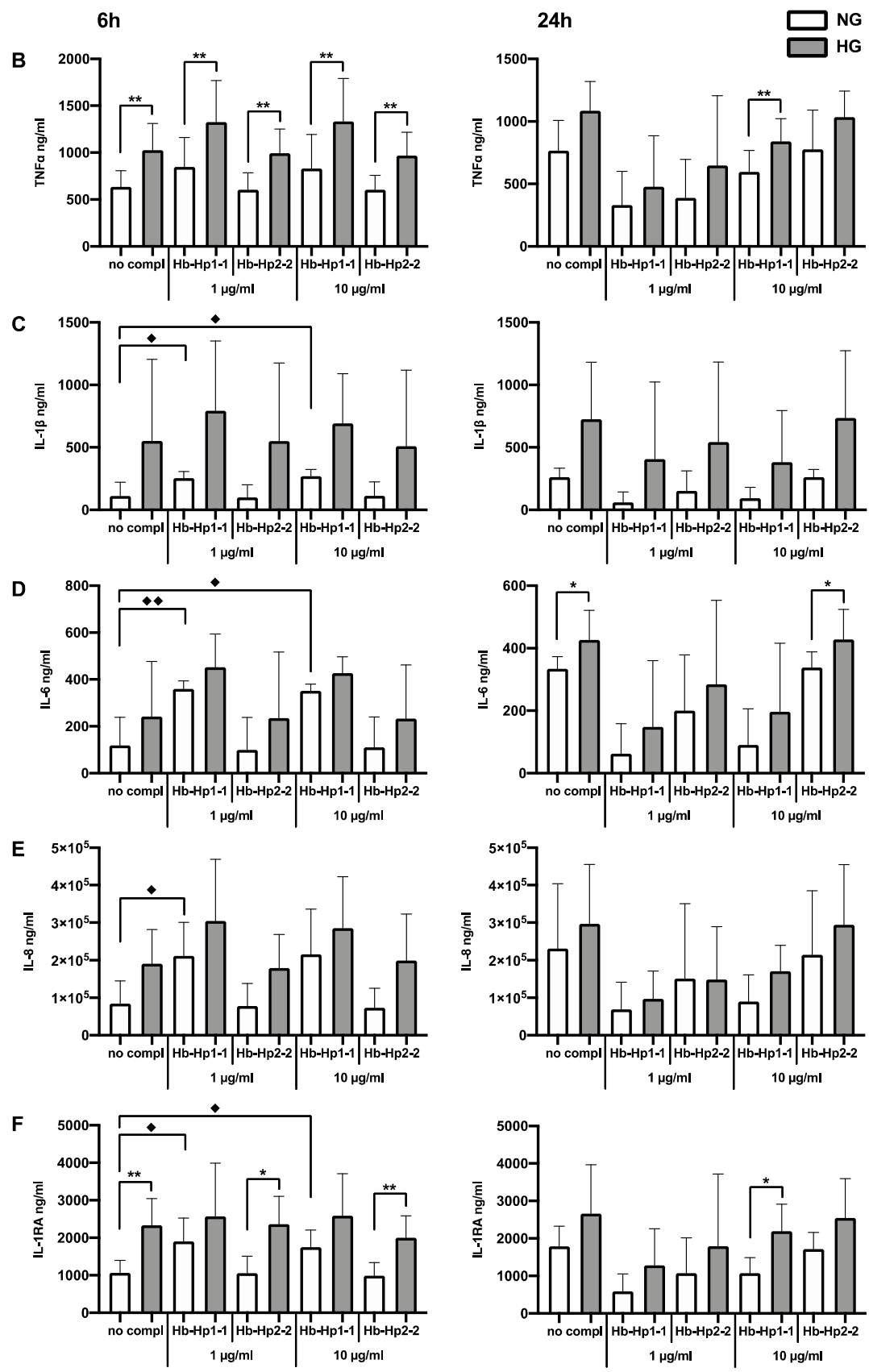

Figure 3. Effect of $\mathrm{Hb}-\mathrm{Hp}$ complexes on the secretion of TNF $\alpha$, IL-1 $\beta$, IL-6, IL-8, and IL-1RA by IFN $\gamma$-stimulated human primary macrophages. Monocyte-derived macrophages were stimulated with 
IFN $\gamma$ and cultured for 6 days in normal $(5 \mathrm{mM}, \mathrm{NG})$ and high $(25 \mathrm{mM}, \mathrm{HG})$ glucose conditions. On day 6, Hb-Hp1-1 and Hb-Hp2-2 complexes in 2 different concentrations ( 1 and $10 \mu \mathrm{g} / \mathrm{mL}$ ) were added to the cells or, serving as a negative control, no complexes ('no compl') were added. The amounts of TNF $\alpha$, IL-1 $\beta$, IL- 6 , and IL- 8 and IL-1RA were detected in the supernatants by the according ELISAs 6 and $24 \mathrm{~h}$ after stimulation with $\mathrm{Hb}-\mathrm{Hp}$ complexes. (A): Schematic presentation of the experimental design used to examine whether stimulation with $\mathrm{Hb}-\mathrm{Hp}$ complexes affects the inflammatory activation of M(IFN $\gamma)$. (B): TNF $\alpha$ secretion; (C): IL-1 $\beta$ secretion; (D): IL-6 secretion; (E): IL-8 secretion; (F): IL-1RA secretion (mean values of 5 donors \pm SD). For statistical analysis, paired $t$ tests were used. * denotes statistical significance between normal- and high-glucose conditions $\left.{ }^{*} p<0.05,{ }^{* *} p<0.01\right) \diamond$ denotes statistical significance between no stimulation and stimulation with Hb-Hp1-1 complexes after $6 \mathrm{~h}(\diamond p<0.05, \diamond p<0.01)$.

The release of proinflammatory IL- $1 \beta$ was significantly increased $6 \mathrm{~h}$ after the stimulation with $\mathrm{Hb}-\mathrm{Hp} 1-1$ complexes in NG for both complex concentrations $(1 \mu \mathrm{g} / \mathrm{mL}: 2.29$ times, $p$-value $<0.05 ; 10 \mu \mathrm{g} / \mathrm{mL}: 2.43$ times, $p$-value $<0.05$, Figure 3C). Hyperglycemia elicited a strong enhancement of IL-1 $\beta$ release after stimulation with $\mathrm{Hb}-\mathrm{Hp}$ complexes regardless of the Hp variant, with the strongest effect being detected $24 \mathrm{~h}$ after stimulation with $1 \mu \mathrm{g} / \mathrm{mL}$ $\mathrm{Hb}-\mathrm{Hp} 1-1$ complexes (6.75 times). However, statistical significance was not reached due to individual donor responses. Then, $24 \mathrm{~h}$ after the stimulation with $\mathrm{Hb}-\mathrm{Hp} 1-1$ complexes, IL-1 $\beta$ secretion was suppressed in both normo- and hyperglycemic conditions, with the strongest suppression detected in NG after stimulation with $1 \mu \mathrm{g} / \mathrm{mL} \mathrm{Hb}-\mathrm{Hp} 1-1$ complexes (4.21 times, $p$-value $<0.01$ ) and 2.89 times after stimulation with $10 \mu \mathrm{g} / \mathrm{mL} \mathrm{Hb-Hp1-1}$ complexes $(p$-value $<0.01)$. In HG, the suppression of IL-1 $\beta$ release was not as pronounced as in NG $(1 \mu \mathrm{g} / \mathrm{mL}$ : 1.95 times, $p$-value $<0.01 ; 10 \mu \mathrm{g} / \mathrm{mL}: 1.81$ times, $p$-value $<0.05)$. The stimulation with 1 or $10 \mu \mathrm{g} / \mathrm{mL} \mathrm{Hb}-\mathrm{Hp} 2-2$ complexes did not elicit any significant effect on IL-1 $\beta$ release compared to non-stimulated $M(\operatorname{IFN} \gamma)$, neither in normoglycemic nor in hyperglycemic conditions after $6 \mathrm{~h}$. After $24 \mathrm{~h}$, however, IL-1 $\beta$ secretion was enhanced compared to $6 \mathrm{~h}$ after stimulation with $10 \mu \mathrm{g} / \mathrm{mL} \mathrm{Hb}-\mathrm{Hp} 2-2$ complexes (NG: 2.32 times, p-value < 0.01; HG: 1.44 times, $p$-value $<0.01)$.

The release of the proinflammatory cytokine IL- 6 was significantly enhanced in NG $6 \mathrm{~h}$ after the stimulation with $\mathrm{Hb}-\mathrm{Hp} 1-1$ complexes $(1 \mu \mathrm{g} / \mathrm{mL}: 3.03$ times, $p$-value $<0.01$; $10 \mu \mathrm{g} / \mathrm{mL}: 2.96$ times, $p$-value $<0.05$ times, Figure 3D). Then, $24 \mathrm{~h}$ after the stimulation with Hb-Hp1-1 complexes, suppression of IL-6 secretion was measured in both normoand hyperglycemia, with the strongest suppression detected in NG after stimulation with $1 \mu \mathrm{g} / \mathrm{mL}$ Hb-Hp1-1 complexes (5.78 times, $p$-value < 0.001) and 3.9 times suppression after stimulation with $10 \mu \mathrm{g} / \mathrm{mL} \mathrm{Hb}-\mathrm{Hp} 1-1$ complexes ( $p$-value < 0.01). In HG, the suppression of IL-6 release was not as pronounced as in NG $(1 \mu \mathrm{g} / \mathrm{mL}: 3.05$ times, $p$-value $<0.001$; $10 \mu \mathrm{g} / \mathrm{mL}$ : 2.17 times, $p$-value < 0.05). The stimulation with 1 or $10 \mu \mathrm{g} / \mathrm{mL} \mathrm{Hb-Hp2-2}$ complexes did not elicit any statistically significant effect on IL-6 release after $6 \mathrm{~h}$ compared to non-stimulated $\mathrm{M}(\operatorname{IFN} \gamma)$, neither in normoglycemic nor in hyperglycemic conditions. However, after $24 \mathrm{~h}$, enhanced IL-6 secretion was detected after stimulation with $10 \mu \mathrm{g} / \mathrm{mL}$ $\mathrm{Hb}$-Hp2-2 complexes in NG (3.06 times, $p$-value < 0.01). In hyperglycemic conditions in general, the release of IL-6 was elevated; however, a statistically significant effect could only be detected $24 \mathrm{~h}$ after stimulation with $10 \mu \mathrm{g} / \mathrm{mL} \mathrm{Hb}-\mathrm{Hp} 2-2$ complexes (1.26 times enhancement, $p$-value $<0.05)$.

The release of IL- 8 was significantly enhanced $6 \mathrm{~h}$ after the stimulation with $1 \mu \mathrm{g} / \mathrm{mL}$ Hb-Hp1-1 complexes in NG (2.51 times, $p$-value $<0.05$, Figure 3E). Then, $24 \mathrm{~h}$ after the stimulation with $\mathrm{Hb}-\mathrm{Hp} 1-1$ complexes, suppression of IL-8 secretion was detected in both NG and HG, with the strongest suppression detected in NG after stimulation with $1 \mu \mathrm{g} / \mathrm{mL}$ $\mathrm{Hb}-\mathrm{Hp} 1-1$ complexes (3.06 times, $\mathrm{p}$-value $<0.05$ ) and 2.4 times suppression after stimulation with $10 \mu \mathrm{g} / \mathrm{mL} \mathrm{Hb}-\mathrm{Hp} 1-1$ complexes ( $p$-value < 0.05). In HG, only the stimulation with $10 \mu \mathrm{g} / \mathrm{mL} \mathrm{Hb}-\mathrm{Hp} 1-1$ complexes suppressed IL-8 release in a statistically significant way (1.67 times, $p$-value $<0.05$ ). The stimulation with $\mathrm{Hb}-\mathrm{Hp} 2-2$ complexes did not elicit any statistically significant change in IL-8 release after $6 \mathrm{~h}$. Moreover, $24 \mathrm{~h}$ after stimulation 
with $10 \mu \mathrm{g} / \mathrm{mL} \mathrm{Hb}-\mathrm{Hp} 2-2$ complexes in HG, significantly enhanced IL-8 secretion was detected compared to $6 \mathrm{~h}$ (1.48 times, $p$-value $<0.05)$. In hyperglycemic conditions, a trend towards increased IL-8 secretion was detected 6 and 24 h after Hb-Hp complex stimulation; however, no statistically significant effect was identified due to donor-specific responses.

The secretion of the anti-inflammatory cytokine IL-1RA was enhanced $6 \mathrm{~h}$ after stimulation with Hb-Hp1-1 complexes in both normo- and hyperglycemia; however, the effect was only statistically significant in NG $(1 \mu \mathrm{g} / \mathrm{mL}$ : 1.8 times, $p$-value $<0.05 ; 10 \mu \mathrm{g} / \mathrm{mL}$ : 1.66 times, $p$-value $<0.05$, Figure 3F). Moreover, $24 \mathrm{~h}$ after the stimulation with Hb-Hp1-1 complexes, suppression of IL-1RA secretion was measured in both NG and HG, with the strongest suppression detected in NG after stimulation with $1 \mu \mathrm{g} / \mathrm{mL} \mathrm{Hb}-\mathrm{Hp} 1-1$ complexes (3.24 times, $p$-value $<0.05$ ) and 1.62 times after stimulation with $10 \mu \mathrm{g} / \mathrm{mL} \mathrm{Hb}-\mathrm{Hp} 1-1 \mathrm{com}-$ plexes ( $p$-value < 0.01). Hyperglycemia enhanced IL-1RA secretion after all stimulations; however, the effect was only statistically significant $6 \mathrm{~h}$ after stimulation with $\mathrm{Hb}-\mathrm{Hp} 2-2$ complexes $(1 \mu \mathrm{g} / \mathrm{mL}: 2.24$ times, $p$-value < 0.05; $10 \mu \mathrm{g} / \mathrm{mL}: 2.03$ times, $p$-value < 0.01) and $24 \mathrm{~h}$ after stimulation with $10 \mu \mathrm{g} / \mathrm{mL} \mathrm{Hb}$-Hp1-1 complexes (2.04 times, $p$-value $<0.05$ ).

$\mathrm{Hb}-\mathrm{Hp} 1-1$ complex uptake was the strongest stimulus for $\mathrm{M}(\mathrm{IFN} \gamma)$ for the acute $(6 \mathrm{~h})$ release of proinflammatory cytokines $\mathrm{TNF} \alpha$, IL-1 $\beta$, IL-6, and IL- 8 and anti-inflammatory IL-1RA, where the strongest effect was identified for IL-6 (3.03 times, $p$-value $<0.01)$. However, $24 \mathrm{~h}$ after $\mathrm{Hb}-\mathrm{Hp} 1-1$ complex uptake $(1 \mu \mathrm{g} / \mathrm{mL})$, the initially detected cytokine release was suppressed in normoglycemic conditions, with the strongest effect being detected for IL-6 (5.78 times; $p$-value < 0.001, Figure 3D) and IL-1 $\beta$ (4.21 times; $p$-value $<0.01$, Figure 3C). Hyperglycemia interfered with $\mathrm{Hb}-\mathrm{Hp} 1-1-$ mediated suppression for all cytokines (e.g., IL-6: only 3.05 times suppression in HG, Figure 3D; IL-1 $\beta$ : only 1.95 times suppression in HG, Figure 3C). Contrarily, Hb-Hp2-2 complex uptake did not affect cytokine release in a significant way after $6 \mathrm{~h}$ but increased the secretion of all read-out cytokines after $24 \mathrm{~h}$, with the release of IL-6 being stimulated the most (3.06 times, $p$-value $<0.01)$. Overall, the strongest enhancing effect of hyperglycemia was detected for IL-1 $\beta$ release $24 \mathrm{~h}$ after $\mathrm{M}(\mathrm{IFN} \gamma)$ was stimulated with $1 \mu \mathrm{g} / \mathrm{mL} \mathrm{Hb}-\mathrm{Hp} 1-1$ complexes (6.75 times).

\section{Discussion}

In order to sustainably treat the skyrocketing number of patients affected by microvascular complications of diabetes mellitus, it is crucial to broaden our understanding of the immunological mechanisms leading to a derogated control of vascular damage [5,42]. In our study, we addressed the hypothesis that hyperglycemia can convert the silent clearance function of monocytes to an inflammatory response and examined this hypothesis by analysis of the clearance of hemoglobin-haptoglobin complexes. As a result, our study identifies a new mechanism of hyperglycemia-amplified inflammation by affecting hemoglobinhaptoglobin interactions with the innate immune system. In this study, we show for the first time that hyperglycemia interferes with the tolerogenic hemoglobin-haptoglobin scavenging process via CD163 by human primary macrophages, and elevates the production of inflammatory cytokines in response to hemoglobin-haptoglobin complex uptake.

So far, a number of studies have tried to elucidate the role and regulation of CD163 in pathological conditions, such as diabetes mellitus or inflammation, altogether $[32,33,43,44]$. In recent studies, mainly samples of already differentiated tissue macrophages $[33,45]$, undifferentiated peripheral blood mononuclear cells [32], or the plasma concentration of the shed receptor, soluble CD163 [46,47], were used. Compared to them, our group used human primary peripheral blood macrophages derived from circulating monocytes.

We showed that IFN $\gamma$ alone is an effective suppressor of CD163 expression on human primary macrophages, thus impairing the scavenging capacity of proinflammatory macrophages. These results, although being observed after a longer duration of cultivation (6 days), correlate with the findings of other studies in which CD163 mRNA and surface expression were decreased on freshly isolated or one-day old peripheral blood monocytes from healthy individuals after IFN $\gamma$ stimulation $[22,26]$. 
Remarkably, we found a discrepancy between CD163 gene and surface expression in M(IL-4) compared to M0. Whereas the mRNA expression of CD163 was significantly downregulated in M(IL-4) compared to M0, the surface expression of CD163 was not affected by stimulation with IL-4. In agreement with this observation, Staples et al. described a downregulation of CD163 mRNA expression upon stimulation with IL-4 [48] and both Sulahian et al. and van den Heuvel et al. demonstrated that stimulation with IL-4 did not alter CD163 surface expression compared to M0 [23,27]. Thus, healing macrophages should possess a compensatory mechanism to ensure sufficient levels of surface CD163 to ensure control over the inflammatory response.

Apart from IFN $\gamma$ - and IL-4-mediated regulation of CD163, hyperglycemia elicited an additional suppression of CD163 mRNA in M(IFN $\gamma)$ compared to normoglycemia. This finding is in line with the observation that CD163 mRNA expression in PBMCs of diabetic individuals was significantly lower compared to PBMCs of healthy subjects [32]. Additionally, clinical studies not only found that pre-diabetic subjects displayed a significant increase in proinflammatory $\mathrm{M}(\mathrm{IFN} \gamma)$, but also showed that diabetic patients had an elevated M1/M2 ratio correlating with a higher prevalence of microangiopathy [42,49].

The decrease of CD163 surface expression in hyperglycemia is congruent with the results of Levy et al., who found that PBMCs acquired from diabetic individuals expressed significantly less CD163 on their cell surface than those from healthy donors [33]. This reduced scavenging capacity might lead to an elevated heme toxicity contributing to endothelial damage and indicating the susceptibility of the diabetic patient to vascular complications due to dysfunctional control of tissue damage $[5,50]$. The clinically observed heterogeneity of manifestation and onset of vascular diabetic complications correlates with the observed donor-dependent response of macrophages to hyperglycemia. We show that cytokines, such as IFN $\gamma$ and IL-4, define the direction of macrophage response, whereas hyperglycemia interferes by enhancing or annulating this cytokine effect.

Suppression of CD163 expression in M(IFN $\gamma)$ in hyperglycemia raised the question of whether high-glucose conditions additionally have a direct impact on the scavenging function of CD163. Although the two tested variants of CD163's ligand haptoglobin Hp1-1 and Hp2-2 differ considerably in their molecular structure [34,51], the uptake patterns of $\mathrm{Hb}-\mathrm{Hp}$ complexes matched CD163 mRNA and surface expression patterns. Remarkably, higher uptake was found for $\mathrm{Hb}-\mathrm{Hp} 2-2$ complexes compared to $\mathrm{Hb}-\mathrm{Hp} 1-1$ complexes in all three macrophage subpopulations, correlating with a higher affinity of the Hp2-2 variant for the CD163-binding site located in the scavenger receptor cysteine-rich (SRCR) domain 3 [21,52]. Whether the structure of haptoglobin itself is the crucial factor in the process of $\mathrm{Hb}-\mathrm{Hp}$ complex internalization is still controversial. An in vitro study performed on monocytes showed that the uptake of $\mathrm{Hb}$-Hp complexes is competitively inhibited by free hemoglobin, thus indicating a common binding site of free and complexed hemoglobin and demonstrating that CD163-hemoglobin interactions are not affected by changes in structure resulting from the binding process of hemoglobin to haptoglobin [53]. This seems to be in contradiction to various other studies describing CD163 as the specific receptor for hemoglobin complexed to haptoglobin but not the free hemoglobin molecule [21,39].

To the best of our knowledge, there have not been any studies reporting a qualitative derogation of the CD163 scavenging function. However, the clinically observed proneness to vascular complications in diabetic patients is enhanced by the limited availabilityand therefore limited capacity to mitigate vessel damage-of CD163 in proinflammatory conditions [50].

As no functional impairment of $\mathrm{Hb}-\mathrm{Hp}$ complex uptake via CD163 was detected, we analyzed whether the uptake itself can provoke an inflammatory activation of macrophages. $\mathrm{M}(\mathrm{IFN} \gamma)$ was chosen as the read-out macrophage subpopulation, taking into account that hyperglycemia is able to polarize macrophages towards an M1-like phenotype [13] and the clinical observation of an increased M1/M2 ratio in diabetics [42]. In vitro studies showed the activation of protein-kinase $C$ - and casein-kinase-dependent macrophage pathways by cross-linking of cell surface CD163, triggering the release of proinflammatory cytokines, 
such as IL-1 $\beta$ and IL-6 [23,54,55]. Moreover, it was found in human atherosclerotic plaques that the exposure to $\mathrm{Hb}-\mathrm{Hp}$ complexes leads to a particular macrophage phenotype, named $\mathrm{M}(\mathrm{Hb})$ or Mhem $[56,57]$. This phenotype is characterized by an abundant expression of surface CD163, downregulated cytokine production, and the lack of lipid withholding [58-60]. As these macrophages are particularly present in areas of hemorrhage and neoangiogenesis, a role in plaque vascularization, microvessel leakage, and inflammation of the surrounding endothelium has been suggested [56], thus questioning the long-established notion that $\mathrm{CD} 163^{+}$macrophages are involved in the resolution of inflammation [26,50]. Adding to a possible role of CD163 in proinflammatory macrophage activation, alveolar spaces of severely infected COVID-19 lungs contained a large amount of CD163 ${ }^{+}$macrophages as a sign of altered airway macrophage populations and correlating with diffuse alveolar damage and worse patient outcomes [61]. Moreover, the serum levels of soluble CD163, as a marker of macrophage activation, were enhanced in COVID-19 patients [62,63].

As a possible factor contributing to diverging results, the haptoglobin variants Hp1-1 and Hp2-2 were found to have not only differences in function, but also in the involvement in pathological conditions. For instance, the clearance and antioxidant capacity of Hp1-1 by binding hemoglobin was superior to the clearance of Hp2-2 [38,39]. The release of anti-inflammatory IL-10 in response to the binding of Hb-Hp1-1 complexes to CD163 was increased compared to $\mathrm{Hb}-\mathrm{Hp} 2-2$ complexes [64]. Regarding the clinical significance of the different haptoglobin variants, it has been shown in longitudinal prospective studies that the Hp2-2 phenotype is an independent risk factor for the development of cardiovascular disease in diabetic individuals in comparison with the homozygous Hp1 variant $[34,40]$. Additionally, it has been demonstrated that CD163 is downregulated in macrophages of atherosclerotic plaques of diabetic patients with the Hp2-2 genotype, indicating a constrained hemoglobin clearing capacity [33].

To detect the inflammatory response of $\mathrm{Hb}$-Hp scavenging in hyperglycemic conditions, we selected a number of read-out cytokines displaying the complex interaction and different stages of an inflammatory reaction. In healthy individuals, the process of inflammation serves a homeostatic purpose, containing pro- and anti-inflammatory phases [65]. In individuals suffering from type 2 diabetes mellitus, however, the balance is tilted towards the proinflammatory side, manifested by an upregulation of proinflammatory intracellular pathways [66] and an elevation in circulating inflammatory markers, such as C-reactive protein, IL-6, and TNF $\alpha$ [67-69].

We showed that hyperglycemia enhanced the proinflammatory response of $\mathrm{M}(\mathrm{IFN} \gamma)$ to $\mathrm{Hb}-\mathrm{Hp}$ complex uptake by stimulating the production of $\mathrm{TNF} \alpha$, IL-1 $\beta$, IL- 6 , IL-8, and IL-1RA, supporting the observation that hyperglycemia itself can induce the secretion of proinflammatory cytokines [6].

A statistically significant increase in TNF $\alpha$ secretion, the 'classical player' of the acutephase immune response [70], could only be detected $6 \mathrm{~h}$ after the stimulation with $\mathrm{Hb}-\mathrm{Hp}$ complexes in hyperglycemia, regardless of the present haptoglobin variant. This finding corresponded to the clinical observation of elevated TNF $\alpha$-levels being detected in newly diagnosed diabetic patients compared to a healthy cohort [71,72].

We found that in response to the uptake of $\mathrm{Hb}-\mathrm{Hp} 1-1$ complexes, out of all the tested cytokines, the most pronounced effects were detected for IL-6. IL-6 plays a key role in the regulation of acute-phase protein production by hepatocytes, upregulating, among others, the secretion of haptoglobin and C-reactive protein [73]. Elevated IL-6 release might contribute to diabetes progression, as an in vitro study reported the induction of cellular insulin resistance of hepatocytes by IL-6-triggered impairment of insulin receptor signal transduction [74]. Another in vitro study showed that lower concentrations $(20 \mu \mathrm{g} / \mathrm{mL})$ of $\mathrm{Hb}-\mathrm{Hp} 1-1$ complexes induced the secretion of proinflammatory IL-6 while higher concentrations $(100 \mu \mathrm{g} / \mathrm{mL})$ of $\mathrm{Hb}-\mathrm{Hp} 1-1$ complexes, however, led to increased CD163 surface expression on monocytes, in terms of a positive anti-inflammatory feedback loop [75].

We found that hyperglycemia increased the secretion of both IL- $1 \beta$ and its natural inhibitor IL-1RA, confirming our previous data [6]. Increased IL-1RA secretion could be a 
possible compensation mechanism or negative feedback for the enhanced release of IL- $1 \beta$, whose serum level was found to be elevated in diabetic patients, contributing to insulin resistance and progression of atherosclerotic lesions in obesity [76]. A compensatory role of IL-1RA might also be an explanation for the controversial observations concerning IL-1RA levels in hyperglycemia: on the one hand, elevated IL-1RA levels could be correlated with insulin resistance [75,77]; on the other hand, IL-1RA was found to diminish markers of inflammation in the blood samples of diabetic patients and enhance beta cell function [78].

In general, $\mathrm{Hb}-\mathrm{Hp} 1-1$ complex uptake was the strongest stimulus for $\mathrm{M}(\mathrm{IFN} \gamma)$ for acute (6 h) cytokine release; however, cytokine secretion was diminished after $24 \mathrm{~h}$. Contrarily, $\mathrm{Hb}-\mathrm{Hp} 2-2$ complex uptake resulted in the increased secretion of all read-out cytokines after $24 \mathrm{~h}$, indicating a transcriptional upregulation of cytokine production. Our in vitro finding that $\mathrm{Hb}-\mathrm{Hp} 2-2$ complex uptake is able to create a long-lasting elevated release of proinflammatory cytokines is in line with the numerous clinical observations of Hp2-2 possessing a lesser antioxidative capacity than Hp1-1 [38,39], inducing a lesser anti-inflammatory response than Hp1-1 [64] and even being an independent risk factor for the development of cardiovascular disease in diabetic patients $[34,40]$.

As an element of the pathophysiology of diabetes, these mechanisms promote the low-grade chronic inflammation present in the vascular system of diabetic patients and support the development of vascular complications. This shows that-in addition to a more proinflammatory setting-diabetes mellitus is a disease characterized by less effective anti-inflammatory damage control $[5,65]$.

However, our study was limited to an ex vivo analysis of the response of primary human monocyte-derived macrophages, and the examination of metabolic syndrome patients or patients with untreated diabetes is necessary to validate the effect of hyperglycemia on the clearance of $\mathrm{Hp}-\mathrm{Hb}$ complexes. The model we used enabled specific identification of the effect of hyperglycemia on $\mathrm{Hp}-\mathrm{Hb}$ clearance and inflammatory programming in human monocyte-derived macrophages. Further research using monocytes isolated from patients with non-compensated hyperglycemia is needed to validate our findings, and to determine the level of contribution of the $\mathrm{Hp}-\mathrm{Hb}$-induced inflammatory monocyte response to systemic inflammation. We also believe that in the future, the effect of currently used medications for diabetic patients should also be analyzed for their ability to minimize $\mathrm{Hp}-\mathrm{Hb}$-induced inflammation.

\section{Materials and Methods}

\subsection{Isolation of Monocytes and Cultivation of Macrophages}

Human monocytes were isolated by density gradient centrifugation from buffy coats of individual healthy donors provided by the blood bank of the DRK-Blutspendedienst Baden-Württemberg-Hessen in Mannheim [79]. In total, $30 \mathrm{~mL}$ of buffy coat were mixed with Dulbecco's Phosphate-Buffered Saline (DPBS, Biochrom, Berlin, Germany) at a 1:1 ratio. The mixture was added on top of $15 \mathrm{~mL}$ of Biocoll (Biochrom, Berlin, Germany) and centrifuged for $30 \mathrm{~min}$ at $420 \mathrm{rcf}$ (Hettich, Rotina, Tuttlingen, Germany). From the white interphase of the Ficoll gradient, peripheral blood mononuclear cells (PBMCs) were collected and washed twice with DPBS. The Percoll gradient was prepared using $13.5 \mathrm{~mL}$ of Percoll ${ }^{\mathrm{TM}}$ (GE Healthcare, Solingen, Germany), $15 \mathrm{~mL}$ of Minimum Essential Medium (MEM, Sigma Aldrich, St. Louis, MO, USA), and $1.5 \mathrm{~mL}$ of Earle's Balanced Salt Solution (EBSS, Sigma Aldrich, St. Louis, MO, USA). PBMCs were layered on the Percoll gradient and the coating containing monocytes was collected after 30 min of centrifugation at $420 \mathrm{rcf}$ (Hettich, Rotina, Tuttlingen, Germany). After two washing steps, the cells were mixed with $\mathrm{CD} 14^{+}$magnetic beads according to the cell sorting protocol of Miltenyi Biotech's monocyte isolation kit (Bergisch Gladbach, Germany). The monocytes were counted using a Casy ${ }^{\mathrm{TM}}$ cell counter (OLS OMNI Life Science GmbH \& Co. KG, Bremen, Germany) and the purity was controlled by flow cytometry. Ex vivo differentiation of monocyte-derived macrophages in normoglycemic and hyperglycemic conditions was performed as previously described [6,7]. Briefly, $1 \times 10^{6}$ monocytes per ml were cultured in Serum-Free 
Medium (Life Technology, Merck KGaA, Darmstadt, Germany) containing $5 \mathrm{mM}$ glucose or $25 \mathrm{mM}$ glucose for a duration of 6 days at $37^{\circ} \mathrm{C}$ in $7.5 \% \mathrm{CO}_{2}$. The added cytokines were purchased from TEBU Preprotech (Frankfurt am Main, Germany). Human IFN $\gamma$ was used at a concentration of $100 \mathrm{ng} / \mathrm{mL}$, human IL-4 at a concentration of $10 \mathrm{ng} / \mathrm{mL}$, dexamethasone at a concentration of $10^{-8} \mathrm{M}$, and human M-CSF at a concentration of $5 \mathrm{ng} / \mathrm{mL}$. Cell viability was assessed using alamarBlue ${ }^{\mathrm{TM}}$ (Supplementary Figure S1).

\subsection{RNA Samples, cDNA Synthesis, and Real-Time PCR Analysis}

For RNA isolation, the cell lysis was performed directly in plastic Petri dishes. The RNA was isolated using an E.Z.N.A. total RNA kit (Omega Bio-Tek Inc., Norcross, GA, USA) according to the manufacturer's protocol. Up to $1 \mu \mathrm{g}$ of RNA was added to $1 \mu \mathrm{g}$ of DNase I (RNase free, Thermo Fisher Scientific, Dreieich, Germany). To synthesize cDNA, Oligo DT primer and Reverse Transcriptase purchased from Thermo Fisher Scientific, Germany were used (RevertAid RT Transcription kit). The cDNA was diluted with $\mathrm{ddH}_{2} \mathrm{O}$ at a 1:10 ratio.

Real-time PCR analysis of CD163 was performed using $0.5 \mu \mathrm{L}$ of cDNA. The mRNA level was quantified using TaqMan PCR mastermix (Applied Biosystems, Darmstadt, Germany). As a reference gene, 18s rRNA was used to normalize the expression levels of the genes analyzed. The primers for human CD163 were designed with MWG Biotech/GeneScript. As a forward primer F2101 (TAGTGAGTGTGGGCACAAGG), as a reversed primer R2102 (CCGACTGCAATAAAGGATGA), and as probe Pr2102 (CACAACAGGTCGCTCATCCCG), all purchased from Eurofins Genomics, Ebersberg, Germany, were found to have an appropriate efficacy. The amplification was performed by a Light Cycler 480 system (Roche Life Science, Penzberg, Germany). The values are displayed as the average of the measurement of three replicates.

\subsection{Flow Cytometry}

Flow cytometry analysis of CD163 surface expression on differentially activated macrophages after 6 days of culture in low $(5 \mathrm{mM})$ and high $(25 \mathrm{mM})$ glucose conditions was performed at the Flow Cytometry Core Facility of the Institute of Transfusion Medicine and Immunology, Medical Faculty Mannheim, University of Heidelberg, Mannheim, Germany. The cells were stained with anti-human CD163 and anti-CD14 for 30 min on ice using the following antibodies: FITC-conjugated mouse IgG1 $\kappa$ anti-CD14 antibody, APC-conjugated mouse IgG1 $\mathrm{k}$ anti-human CD163, FITC-conjugated mouse IgG1k isotype control; APCconjugated mouse IgG1 $\mathrm{\kappa}$ isotype control (all purchased from eBioscience Inc., San Diego, CA, USA). Human TruStain FCX (Fc Receptor blocking solution) was purchased from Biolegend Inc., San Diego, CA, USA. Fluorescence intensity was measured using a BD FACS Canto II (Becton Dickinson, Franklin Lakes, NJ, USA) equipped with the BD FACSDiva software (Becton Dickinson, Franklin Lakes, NJ, USA). The values are displayed as the average of the measurement of three replicates. Data analysis was performed using the FlowJo software (FlowJo, Becton Dickinson, Franklin Lakes, NJ, USA). The gating of monocytes and macrophages was based on forward-sideward scatter profiles (shown in Supplementary Figure S2). The cells were stained with a PE-conjugated mouse IgG2ak anti-human HLA-DR antibody (Biozol Diagnostica Vertrieb GmbH, Eching, Germany), which was used as a cell viability marker (Supplementary Figure S3).

\subsection{ELISA}

Supernatants of macrophages were harvested on day 6 of cultivation in NG and HG conditions. The concentrations of the cytokines IL-1 $\beta$, IL-1RA, IL-6, IL- 8 , and TNF $\alpha$ in the supernatants were measured by ELISA (Human IL-1 $\beta$ DuoSet ELISA kit (dilution of samples: 1:2), Human IL-1RA DuoSet ELISA kit (dilution of samples: 1:50), Human IL-6 DuoSet ELISA kit (dilution of samples: 1:2), Human IL-8 DuoSet ELISA kit (dilution of samples: 1:50), and Human TNF $\alpha$ DuoSet ELISA kit (dilution of samples: 1:2)) according to the protocols of the manufacturer (R\&D Systems, Minneapolis, MN, USA). After bringing 
all components to room temperature, the plates were prepared by diluting the capture antibody to a working concentration in PBS. After incubation overnight, the plate was washed (0.05\% Tween 20 in PBS; pH: 7.2-7.4) and blocked by Reagent Diluent (1\% BSA in PBS; pH: 7.2-7.4). The standard was diluted according to the manufacturer's protocol. Samples were thawed and diluted as indicated above. The standard was pipetted in a serial dilution in the first two columns of the plate. After adding the samples to the rest of the plate, a 2-h incubation, and consecutive washing step, $100 \mu \mathrm{L}$ of detection antibody were added per well. After another incubation period of $2 \mathrm{~h}$ and washing step, $100 \mu \mathrm{L}$ of Streptavidin-HRP were added to each well. After a 20-min period of incubation in the dark, $100 \mu \mathrm{L}$ of substrate solution (1:1 mixture of Color Reagent $\mathrm{A}\left(\mathrm{H}_{2} \mathrm{O}_{2}\right)$ and Color Reagent B (Tetramethylbenzidine)) were added, followed by 20 min of incubation. In total, $50 \mu \mathrm{L}$ of stop solution $\left(2 \mathrm{~N} \mathrm{H}_{2} \mathrm{SO}_{4}\right)$ were added. Immediately after adding the stop solution, the optical density of each well was determined. A TECAN Infinite 200 microplate reader (Thermo Fisher Scientific, Dreieich, Germany) set to $450 \mathrm{~nm}$ was used. The reference wavelength was set to $570 \mathrm{~nm}$. All samples were measured in duplicate.

\subsection{Endocytosis of $\mathrm{Hp}-\mathrm{Hb}$ Complexes}

Human haptoglobin variants Hp1-1 and Hp2-2 (Sigma Aldrich, St. Louis, MO, USA) were fluorescently labeled with Alexa Fluor ${ }^{\circledR} 488$ according to the Alexa Fluor ${ }^{\circledR} 488$ Protein Labeling Kit procedure (Molecular Probes, Eugene, OR, USA). The extent of labeling was determined using the Thermo Scientific ${ }^{\mathrm{TM}}$ Pierce $^{\mathrm{TM}} \mathrm{BCA}$ Protein Assay Kit (Pierce Biotechnology, Waltham, MA, USA). To build hemoglobin-haptoglobin complexes, human hemoglobin $\left(\mathrm{A}_{0}, 1 \mathrm{mg} / \mathrm{mL}\right.$, Sigma Aldrich, St. Louis, MO, USA) was added to previously labeled Hp1-1 or Hp2-2 and incubated at $37^{\circ} \mathrm{C}$ for $10 \mathrm{~min}$ on a rotator. Subsequently, the complexes were added to macrophages cultured for 6 days in NG and HG conditions. Alexa Fluor ${ }^{\circledR}$ 488-labeled acLDL (Life Technology, Merck KGaA, Darmstadt, Germany) was used as a positive control for macrophage endocytic activity. Macrophages were incubated with fluorescently labeled ligands $(10 \mu \mathrm{g} / \mathrm{mL}$ of $\mathrm{Hb}-\mathrm{Hp} 1-1$ complexes, $10 \mu \mathrm{g} / \mathrm{mL}$ of $\mathrm{Hb}$ Hp2-2 complexes, or $5 \mu \mathrm{g} / \mathrm{mL}$ Alexa Fluor ${ }^{\circledR} 488$-labeled acLDL) for $30 \mathrm{~min}$ at $37^{\circ} \mathrm{C}$ and $7 \% \mathrm{CO}_{2}$. After the endocytosis procedure, macrophages were placed on ice for $60 \mathrm{~min}$. Harvested cells were washed with PBS, and the fluorescence intensity was measured using BD FACS Canto II (Becton Dickinson, Franklin Lakes, NJ, USA) equipped with BD FACSDiva software (Becton Dickinson, Franklin Lakes, NJ, USA). The MFI values of $\mathrm{Hb}-\mathrm{Hp}$ complex uptake were measured in triplicates and calculated by subtracting the MFI values of 'no ligand' controls.

\subsection{Immunofluorescent Staining and Confocal Microscopy}

First, $1 \times 10^{6}$ monocytes per ml were cultured in Serum-Free Medium (Life Technology, Merck KGaA, Darmstadt, Germany) containing 5 or $25 \mathrm{mM}$ glucose for 6 days. The following cytokines were added: human IFN $\gamma(100 \mathrm{ng} / \mathrm{mL})$ or human IL-4 $(10 \mathrm{ng} / \mathrm{mL})$; dexamethasone $\left(10^{-8} \mathrm{M}\right)$; and human M-CSF $(5 \mathrm{ng} / \mathrm{mL})$ (all purchased from TEBU Preprotech (Frankfurt am Main, Germany)). Human haptoglobin variants Hp1-1 and Hp2-2 (Sigma Aldrich, St. Louis, MO, USA) were fluorescently labeled with Alexa Fluor ${ }^{\circledR} 488$ according to the Alexa Fluor ${ }^{\circledR} 488$ Protein Labeling Kit procedure (Molecular Probes, Eugene, OR, USA). To build hemoglobin-haptoglobin complexes, human hemoglobin $\left(\mathrm{A}_{0}, 1 \mathrm{mg} / \mathrm{mL}\right.$, Sigma Aldrich, St. Louis, MO, USA) was added to previously labeled Hp1-1 or Hp2-2 and incubated at $37^{\circ} \mathrm{C}$ for $10 \mathrm{~min}$ on a rotator. Subsequently, the complexes were added to the macrophages after 6 days of culture. Alexa Fluor ${ }^{\circledR}$ 488-labeled acLDL (Life Technology, Merck KGaA, Darmstadt, Germany) was used as a positive control for macrophage endocytic activity. The cells were incubated with fluorescently labeled ligands for $30 \mathrm{~min}$ at $37^{\circ} \mathrm{C}$ under $7 \% \mathrm{CO}_{2}$. Then, the macrophages were harvested and transferred onto glass slides using cytospin centrifuge (Thermo Fisher Scientific, Dreieich, Germany). Fixation of cells on glass slides by PFA and staining was performed as previously described [79]. As primary antibody goat polyclonal anti-human CD163 and as isotype control goat IgG 
'normal goat IgG' (both purchased from Santa Cruz, Biotechnology, Dallas, TX, USA) were used. As secondary antibody donkey anti-goat Cy3 (Dianova, Hamburg, Germany) was used. Nuclei were visualized by DRAQ5 (New England BioLabs, Ipswich, MA, USA).

Confocal laser scanning microscopy was performed using a Leica TCS SP2 laser scanning spectral confocal microscope equipped with a $63 \times 1.32$ objective (Leica Microsystems, Wetzlar, Germany). An argon laser with an emission wavelength of $488 \mathrm{~nm}$, a krypton laser with an emission wavelength of $568 \mathrm{~nm}$, and a helium/neon laser with an emission wavelength of $633 \mathrm{~nm}$ were used to perform excitation. Data were acquired and analyzed with the Leica Confocal software (Leica Microsystems, Wetzlar, Germany). Two- and three-color images were acquired using the sequential scan mode.

\subsection{Inflammatory Response Assay}

$\mathrm{CD} 14^{+}$monocytes of 5 healthy donors were differentiated for 6 days in a serumfree medium complemented with human IFN $\gamma(100 \mathrm{ng} / \mathrm{mL})$ in normal $(5 \mathrm{mM})$ and high $(25 \mathrm{mM})$ glucose conditions. After 6 days of culturing, the macrophages were stimulated with hemoglobin-haptoglobin1-1 complexes or hemoglobin-haptoglobin2-2 complexes in 2 different concentrations ( 1 and $10 \mu \mathrm{g} / \mathrm{mL}$ ). Supernatants were obtained 6 and $24 \mathrm{~h}$ after stimulation with the complexes. Concentrations of IL-1 $\beta$, IL-1RA, IL-6, IL-8, and TNF $\alpha$ were measured by ELISA according to the protocols of the manufacturer (R\&D Systems, Minneapolis, MN, USA) and measured in duplicates. A TECAN Infinite 200 microplate reader (Thermo Fisher Scientific, Dreieich, Germany) set to $450 \mathrm{~nm}$ was used to read the plates. The reference wavelength was set to $570 \mathrm{~nm}$; again, all samples were measured in duplicate.

\subsection{Statistical Analysis}

Statistical analysis was performed using GraphPad Prism 8 software (GraphPad Software Inc., San Diego, CA, USA). The significance of the difference between the two groups of experimental data was determined using the Wilcoxon matched-pairs rank test or a paired $t$ test. We considered a two-tailed $p$-value of less than 0.05 to indicate statistical significance (confidence level 95\%). All graphs were created using the software GraphPad Prism 8.

\section{Conclusions}

Here, we show for the first time that hyperglycemia can affect essential monocyte/ macrophage clearance functions required to eliminate $\mathrm{Hb}-\mathrm{Hp}$ complexes. Hyperglycemia has already been identified as a direct driver of inflammatory cytokine release in monocytes and macrophages. We found that hyperglycemia does not affect internalization of Hp1-1 and Hp2-2 genetic variants, neither in proinflammatory nor in anti-inflammatory macrophages. However, we identified that hyperglycemia enhances the release of inflammatory cytokines in response to scavenging of $\mathrm{Hb}-\mathrm{Hp}$ complexes via $\mathrm{CD} 163$ in $\mathrm{M}(\mathrm{IFN} \gamma)$, converting the silent $\mathrm{Hb}-\mathrm{Hp}$ complex clearing process needed to prevent vascular damage into an inflammatory process. These mechanisms can promote low-grade chronic inflammation in individuals with metabolic syndrome and non-treated diabetes, and can predispose these patients to the development of micro- and macrovascular complications.

Supplementary Materials: Supplementary materials can be found at https:/ /www.mdpi.com/ article/10.3390/ijms23031385/s1.

Author Contributions: Conceptualization, L.M., V.R. and J.K.; Data curation, C.S.; Formal analysis, L.M., V.R., C.S., T.S. and C.W.; Funding acquisition, J.K.; Investigation, L.M. and T.S.; Methodology, L.M., V.R. and J.K.; Project administration, J.K.; Resources, H.K. and J.K.; Supervision, V.R. and J.K.; Visualization, L.M.; Writing-original draft, L.M.; Writing—review \& editing, V.R., C.W., H.K. and J.K. All authors have read and agreed to the published version of the manuscript.

Funding: This research was supported by GRK1874 DIAMICOM (J.K.). 
Institutional Review Board Statement: Not applicable.

Informed Consent Statement: Not applicable.

Acknowledgments: The authors thank Karen Bieback and Stephanie Uhlig for excellent assistance at the FlowCore Mannheim.

Conflicts of Interest: The authors declare no conflict of interest.

\begin{tabular}{|c|c|}
\hline CD & cluster of differentiation \\
\hline DCCT & Diabetes Control and Complications Trial \\
\hline HG & high glucose conditions, hyperglycemia ( $25 \mathrm{mM})$ \\
\hline $\mathrm{Hb}$ & hemoglobin \\
\hline $\mathrm{Hp}$ & haptoglobin \\
\hline M0, M(Control) & non-stimulated macrophages \\
\hline $\mathrm{M}(\mathrm{IFN} \gamma)$ & macrophages stimulated with IFN $\gamma$ \\
\hline $\mathrm{M}(\mathrm{IL}-4)$ & macrophages stimulated with IL-4 \\
\hline M1 & classically activated macrophages \\
\hline M2 & alternatively activated macrophages \\
\hline MFI & mean fluorescence intensity \\
\hline NG & normal glucose conditions, normoglycemia ( $5 \mathrm{mM})$ \\
\hline no compl & 'no complexes' \\
\hline PBMC & peripheral blood mononuclear cells \\
\hline PFA & paraformaldehyde \\
\hline RAGE & receptor for advanced glycation endproducts \\
\hline UKPDS & United Kingdom Prospective Diabetes Study \\
\hline
\end{tabular}

\section{References}

1. Alberti, K.G.; Zimmet, P.Z.; Aschner, P.; Assal, P.-J.; Bennet, P.H.; Groop, L.; Jervell, J.; Kanazawa, Y.; Keen, H.; Klein, R.; et al. Diagnosis and Classification of Diabetes Mellitus; Report of a WHO Consultation; WHO, Department of Noncommunicable Disease Surveillance: Geneva, Switzerland, 1999.

2. Powers, A.; Niswender, K.; Evans-Molina, C. Diabetes: Diagnosis, Classification, and Pathophysiology. In Harrison's Principles of Internal Medicine, 20th ed.; Jameson, F., Kasper, H., Longo, L., Eds.; McGraw-Hill Education: New York, NY, USA, 2018; Volume I, pp. 2850-2859.

3. DCCT. The Diabetes Control and Complications Trial (DCCT). Design and methodologic considerations for the feasibility phase. Diabetes 1986, 35, 530-545. [CrossRef]

4. Stevens, R.J.; Kothari, V.; Adler, A.I.; Stratton, I.M.; United Kingdom Prospective Diabetes Study (UKPDS) Group. The UKPDS risk engine: A model for the risk of coronary heart disease in Type II diabetes (UKPDS 56). Clin. Sci. 2001, 101, 671-679. [CrossRef]

5. Schaper, N.C.; Havekes, B. Diabetes: Impaired damage control. Diabetologia 2012, 55, 18-20. [CrossRef] [PubMed]

6. Moganti, K.; Li, F.; Schmuttermaier, C.; Riemann, S.; Kluter, H.; Gratchev, A.; Harmsen, M.C.; Kzhyshkowska, J. Hyperglycemia induces mixed M1/M2 cytokine profile in primary human monocyte-derived macrophages. Immunobiology 2017, 222, 952-959. [CrossRef]

7. Mossel, D.M.; Moganti, K.; Riabov, V.; Weiss, C.; Kopf, S.; Cordero, J.; Dobreva, G.; Rots, M.G.; Kluter, H.; Harmsen, M.C.; et al Epigenetic Regulation of S100A9 and S100A12 Expression in Monocyte-Macrophage System in Hyperglycemic Conditions. Front. Immunol. 2020, 11, 1071. [CrossRef]

8. Dasu, M.R.; Devaraj, S.; Park, S.; Jialal, I. Increased toll-like receptor (TLR) activation and TLR ligands in recently diagnosed type 2 diabetic subjects. Diabetes Care 2010, 33, 861-868. [CrossRef]

9. Lorenzi, M. The polyol pathway as a mechanism for diabetic retinopathy: Attractive, elusive, and resilient. Exp. Diabetes Res. 2007, 2007, 61038. [CrossRef]

10. Ishibashi, Y.; Matsui, T.; Maeda, S.; Higashimoto, Y.; Yamagishi, S. Advanced glycation end products evoke endothelial cell damage by stimulating soluble dipeptidyl peptidase-4 production and its interaction with mannose 6-phosphate/insulin-like growth factor II receptor. Cardiovasc. Diabetol. 2013, 12, 125. [CrossRef]

11. Wendt, T.M.; Tanji, N.; Guo, J.; Kislinger, T.R.; Qu, W.; Lu, Y.; Bucciarelli, L.G.; Rong, L.L.; Moser, B.; Markowitz, G.S.; et al. RAGE drives the development of glomerulosclerosis and implicates podocyte activation in the pathogenesis of diabetic nephropathy. Am. J. Pathol. 2003, 162, 1123-1137. [CrossRef]

12. Mathur, N.; Pedersen, B.K. Exercise as a mean to control low-grade systemic inflammation. Mediat. Inflamm 2008, $2008,109502$. [CrossRef] 
13. Torres-Castro, I.; Arroyo-Camarena, U.D.; Martinez-Reyes, C.P.; Gomez-Arauz, A.Y.; Duenas-Andrade, Y.; Hernandez-Ruiz, J.; Bejar, Y.L.; Zaga-Clavellina, V.; Morales-Montor, J.; Terrazas, L.I.; et al. Human monocytes and macrophages undergo M1-type inflammatory polarization in response to high levels of glucose. Immunol. Lett. 2016, 176, 81-89. [CrossRef] [PubMed]

14. Heizmann, C.W.; Fritz, G.; Schafer, B.W. S100 proteins: Structure, functions and pathology. Front. Biosci. 2002, 7, d1356-d1368. [PubMed]

15. Chellan, B.; Sutton, N.R.; Bowman, M.A.H. S100/RAGE-Mediated Inflammation and Modified Cholesterol Lipoproteins as Mediators of Osteoblastic Differentiation of Vascular Smooth Muscle Cells. Front. Cardiovasc. Med. 2018, 5, 163. [CrossRef] [PubMed]

16. Xiao, X.; Yang, C.; Qu, S.L.; Shao, Y.D.; Zhou, C.Y.; Chao, R.; Huang, L.; Zhang, C. S100 proteins in atherosclerosis. Clin. Chim. Acta 2020, 502, 293-304. [CrossRef]

17. Buechler, C.; Eisinger, K.; Krautbauer, S. Diagnostic and prognostic potential of the macrophage specific receptor CD163 in inflammatory diseases. Inflamm. Allergy Drug Targets 2013, 12, 391-402. [CrossRef]

18. Fuentes-Duculan, J.; Suarez-Farinas, M.; Zaba, L.C.; Nograles, K.E.; Pierson, K.C.; Mitsui, H.; Pensabene, C.A.; Kzhyshkowska, J.; Krueger, J.G.; Lowes, M.A. A subpopulation of CD163-positive macrophages is classically activated in psoriasis. J. Investig. Dermatol. 2010, 130, 2412-2422. [CrossRef]

19. Larionova, I.; Tuguzbaeva, G.; Ponomaryova, A.; Stakheyeva, M.; Cherdyntseva, N.; Pavlov, V.; Choinzonov, E.; Kzhyshkowska, J. Tumor-Associated Macrophages in Human Breast, Colorectal, Lung, Ovarian and Prostate Cancers. Front. Oncol. 2020, $10,566511$. [CrossRef]

20. Bengtsson, E.; Hultman, K.; Edsfeldt, A.; Persson, A.; Nitulescu, M.; Nilsson, J.; Goncalves, I.; Bjorkbacka, H. CD163+ macrophages are associated with a vulnerable plaque phenotype in human carotid plaques. Sci. Rep. 2020, 10, 14362. [CrossRef]

21. Kristiansen, M.; Graversen, J.; Jacobsen, C.; Sonne, O.; Hoffman, H.J.; Lawk, A.; Moestrup, S. Identifcation of the haemoglobin scavenger receptor. Nature 2001, 409, 198-201. [CrossRef]

22. Buechler, C.; Ritter, M.; Orso, E.; Langmann, T.; Klucken, J.; Schmitz, G. Regulation of scavenger receptor CD163 expression in human monocytes and macrophages by pro- and antiinflammatory stimuli. J. Leukoc. Biol. 2000, 67, 97-103. [CrossRef]

23. Van den Heuvel, M.M.; Tensen, C.P.; van As, J.H.; Van den Berg, T.K.; Fluitsma, D.M.; Dijkstra, C.D.; Dopp, E.A.; Droste, A.; Van Gaalen, F.A.; Sorg, C.; et al. Regulation of CD 163 on human macrophages: Cross-linking of CD163 induces signaling and activation. J. Leukoc. Biol. 1999, 66, 858-866. [CrossRef] [PubMed]

24. Hogger, P.; Dreier, J.; Droste, A.; Buck, F.; Sorg, C. Identification of the integral membrane protein RM3/1 on human monocytes as a glucocorticoid-inducible member of the scavenger receptor cysteine-rich family (CD163). J. Immunol. 1998, 161, 1883-1890. [PubMed]

25. Philippidis, P.; Mason, J.C.; Evans, B.J.; Nadra, I.; Taylor, K.M.; Haskard, D.O.; Landis, R.C. Hemoglobin scavenger receptor CD163 mediates interleukin-10 release and heme oxygenase-1 synthesis: Antiinflammatory monocyte-macrophage responses in vitro, in resolving skin blisters in vivo, and after cardiopulmonary bypass surgery. Circ. Res. 2004, 94, 119-126. [CrossRef] [PubMed]

26. Zwadlo, G.; Voegeli, R.; Schulze Osthoff, K.; Sorg, C. A monoclonal antibody to a novel differentiation antigen on human macrophages associated with the down-regulatory phase of the inflammatory process. Pathobiology 1987, 55, 295-304. [CrossRef]

27. Sulahian, T.H.; Hogger, P.; Wahner, A.E.; Wardwell, K.; Goulding, N.J.; Sorg, C.; Droste, A.; Stehling, M.; Wallace, P.K.; Morganelli, P.M.; et al. Human monocytes express CD163, which is upregulated by IL-10 and identical to p155. Cytokine 2000, 12, $1312-1321$. [CrossRef]

28. Asleh, R.; Levy, A.P. In vivo and in vitro studies establishing haptoglobin as a major susceptibility gene for diabetic vascular disease. Vasc. Health Risk Manag. 2005, 1, 19-28. [CrossRef]

29. Everse, J.; Hsia, N. The toxicities of native and modified hemoglobins. Free Radic. Biol. Med. 1997, 22, 1075-1099. [CrossRef]

30. Schaer, C.A.; Vallelian, F.; Imhof, A.; Schoedon, G.; Schaer, D.J. CD163-expressing monocytes constitute an endotoxin-sensitive $\mathrm{Hb}$ clearance compartment within the vascular system. J. Leukoc. Biol. 2007, 82, 106-110. [CrossRef]

31. Nielsen, M.J.; Andersen, C.B.; Moestrup, S.K. CD163 binding to haptoglobin-hemoglobin complexes involves a dual-point electrostatic receptor-ligand pairing. J. Biol. Chem. 2013, 288, 18834-18841. [CrossRef]

32. Dubayee, M.S.A.; Alayed, H.; Almansour, R.; Alqaoud, N.; Alnamlah, R.; Obeid, D.; Alshahrani, A.; Zahra, M.M.; Nasr, A.; Al-Bawab, A.; et al. Differential Expression of Human Peripheral Mononuclear Cells Phenotype Markers in Type 2 Diabetic Patients and Type 2 Diabetic Patients on Metformin. Front. Endocrinol. 2018, 9, 537. [CrossRef]

33. Levy, A.; Purushothaman, K.R.; Levy, N.S.; Purushothaman, M.; Strauss, M.; Asleh, R.; Marsh, S.; Cohen, O.; Moestrup, S.K.; Moller, H.J.; et al. Downregulation of the hemoglobin scavenger receptor in individuals with diabetes and the Hp 2-2 genotype: Implications for the response to intraplaque hemorrhage and plaque vulnerability. Circ. Res. 2007, 101, 106-110. [CrossRef] [PubMed]

34. Levy, A.; Asleh, R.; Blum, S.; Levy, N.S.; Miller-Lotan, R.; Kalet-Litman, S.; Anbinder, Y.; Lache, O.; Nakhoul, F.M.; Asaf, R.; et al. Haptoglobin: Basic and clinical aspects. Antioxid. Redox Signal. 2010, 12, 293-304. [CrossRef] [PubMed]

35. Langlois, M.R.; Delanghe, J.R. Biological and clinical significance of haptoglobin polymorphism in humans. Clin. Chem. 1996, 42, 1589-1600. [CrossRef] [PubMed]

36. Thomsen, J.H.; Etzerodt, A.; Svendsen, P.; Moestrup, S.K. The Haptoglobin-CD163-Heme Oxygenase-1 Pathway for Hemoglobin Scavenging. Oxid. Med. Cell. Longev. 2013, 2013, 523652. [CrossRef] [PubMed] 
37. Gabay, C.; Kushner, I. Acute-phase proteins and other systemic responses to inflammation. N. Engl. J. Med. 1999, 340, 448-454. [CrossRef] [PubMed]

38. Melamed-Frank, M.; Lache, O.; Enav, B.I.; Szafranek, T.; Levy, N.S.; Ricklis, R.M.; Levy, A.P. Structure-function analysis of the antioxidant properties of haptoglobin. Blood 2001, 98, 3693-3698. [CrossRef]

39. Asleh, R.; Marsh, S.; Shilkrut, M.; Binah, O.; Guetta, J.; Lejbkowicz, F.; Enav, B.; Shehadeh, N.; Kanter, Y.; Lache, O.; et al. Genetically determined heterogeneity in hemoglobin scavenging and susceptibility to diabetic cardiovascular disease. Circ. Res. 2003, 92, 1193-1200. [CrossRef]

40. Levy, A.P.; Hochberg, I.; Jablonski, K.; Resnick, H.E.; Lee, E.T.; Best, L.; Howard, B.V.; Strong Heart, S. Haptoglobin phenotype is an independent risk factor for cardiovascular disease in individuals with diabetes: The Strong Heart Study. J. Am. Coll. Cardiol. 2002, 40, 1984-1990. [CrossRef]

41. Wang, Y.; Kinzie, E.; Berger, F.G.; Lim, S.K.; Baumann, H. Haptoglobin, an inflammation-inducible plasma protein. Redox Rep. 2001, 6, 379-385. [CrossRef]

42. Fadini, G.P.; de Kreutzenberg, S.V.; Boscaro, E.; Albiero, M.; Cappellari, R.; Krankel, N.; Landmesser, U.; Toniolo, A.; Bolego, C.; Cignarella, A.; et al. An unbalanced monocyte polarisation in peripheral blood and bone marrow of patients with type 2 diabetes has an impact on microangiopathy. Diabetologia 2013, 56, 1856-1866. [CrossRef]

43. Etzerodt, A.; Moestrup, S.K. CD163 and Inflammation: Biological, Diagnostic, and Therapeutic Aspects. Antioxid. Redox Signal 2013, 18, 2352-2363. [CrossRef] [PubMed]

44. Moller, H.J.; Frikke-Schmidt, R.; Moestrup, S.K.; Nordestgaard, B.; Tybjærg-Hansen, A. Serum soluble CD163 predicts risk of type 2 diabetes in the general population. Clin. Chem. 2011, 57, 291-297. [CrossRef] [PubMed]

45. Fink, L.N.; Oberbach, A.; Costford, S.R.; Chan, K.L.; Sams, A.; Bluher, M.; Klip, A. Expression of anti-inflammatory macrophage genes within skeletal muscle correlates with insulin sensitivity in human obesity and type 2 diabetes. Diabetologia 2013, 56, 1623-1628. [CrossRef] [PubMed]

46. Aristoteli, L.; Møller, H.J.; Bailey, B.; Moestrup, S.K.; Kritharides, L. The monocytic lineage specific soluble CD163 is a plasma marker of coronary atherosclerosis. Atherosclerosis 2006, 184, 342-347. [CrossRef]

47. Zanni, M.V.; Burdo, T.H.; Makimura, H.; Williams, K.C.; Grinspoon, S.K. Relationship between monocyte/macrophage activation marker soluble CD163 and insulin resistance in obese and normal-weight subjects. Clin. Endocrinol. 2012, 77, 385-390. [CrossRef]

48. Staples, K.J.; Hinks, T.S.; Ward, J.A.; Gunn, V.; Smith, C.; Djukanovic, R. Phenotypic characterization of lung macrophages in asthmatic patients: Overexpression of CCL17. J. Allergy Clin. Immunol. 2012, 130, 1404-1412. [CrossRef]

49. Fadini, G.P.; Cappellari, R.; Mazzucato, M.; Agostini, C.; Vigili de Kreutzenberg, S.; Avogaro, A. Monocyte-macrophage polarization balance in pre-diabetic individuals. Acta Diabetol. 2013, 50, 977-982. [CrossRef]

50. Schaer, C.A.; Schoedon, G.; Imhof, A.; Kurrer, M.O.; Schaer, D.J. Constitutive endocytosis of CD163 mediates hemoglobin-heme uptake and determines the noninflammatory and protective transcriptional response of macrophages to hemoglobin. Circ. Res. 2006, 99, 943-950. [CrossRef]

51. Wejman, J.C.; Hovsepian, D.; Wall, J.S.; Hainfeld, J.F.; Greer, J. Structure and assembly of haptoglobin polymers by electron microscopy. J. Mol. Biol. 1984, 174, 343-368. [CrossRef]

52. Andersen, C.B.; Torvund-Jensen, M.; Nielsen, M.J.; de Oliveira, C.L.; Hersleth, H.P.; Andersen, N.H.; Pedersen, J.S.; Andersen, G.R.; Moestrup, S.K. Structure of the haptoglobin-haemoglobin complex. Nature 2012, 489, 456-459. [CrossRef]

53. Schaer, D.J.; Schaer, C.A.; Buehler, P.W.; Boykins, R.A.; Schoedon, G.; Alayash, A.I.; Schaffner, A. CD163 is the macrophage scavenger receptor for native and chemically modified hemoglobins in the absence of haptoglobin. Blood 2006, 107, 373-380. [CrossRef] [PubMed]

54. Schaer, D.J. The macrophage hemoglobin scavenger receptor (CD163) as a genetically determined disease modifying pathway in atherosclerosis. Atherosclerosis 2002, 163, 199-201. [CrossRef]

55. Ritter, M.; Buechler, C.; Kapinsky, M.; Schmitz, G. Interaction of CD163 with the regulatory subunit of casein kinase II (CKII) and dependence of CD163 signaling on CKII and protein kinase C. Eur. J. Immunol. 2001, 31, 999-1009. [CrossRef]

56. Guo, L.; Akahori, H.; Harari, E.; Smith, S.L.; Polavarapu, R.; Karmali, V.; Otsuka, F.; Gannon, R.L.; Braumann, R.E.; Dickinson, M.H.; et al. CD163+ macrophages promote angiogenesis and vascular permeability accompanied by inflammation in atherosclerosis. J. Clin. Investig. 2018, 128, 1106-1124. [CrossRef] [PubMed]

57. Guo, L.; Harari, E.; Virmani, R.; Finn, A.V. Linking Hemorrhage, Angiogenesis, Macrophages, and Iron Metabolism in Atherosclerotic Vascular Diseases. Arterioscler. Thromb. Vasc. Biol. 2017, 37, e33-e39. [CrossRef] [PubMed]

58. Liberale, L.; Dallegri, F.; Montecucco, F.; Carbone, F. Pathophysiological relevance of macrophage subsets in atherogenesis. Thromb. Haemost. 2017, 117, 7-18. [CrossRef]

59. Finn, A.V.; Nakano, M.; Polavarapu, R.; Karmali, V.; Saeed, O.; Zhao, X.; Yazdani, S.; Otsuka, F.; Davis, T.; Habib, A.; et al. Hemoglobin directs macrophage differentiation and prevents foam cell formation in human atherosclerotic plaques. J. Am. Coll. Cardiol. 2012, 59, 166-177. [CrossRef]

60. Boyle, J.J.; Harrington, H.A.; Piper, E.; Elderfield, K.; Stark, J.; Landis, R.C.; Haskard, D.O. Coronary intraplaque hemorrhage evokes a novel atheroprotective macrophage phenotype. Am. J. Pathol. 2009, 174, 1097-1108. [CrossRef]

61. Szabo, P.A.; Dogra, P.; Gray, J.I.; Wells, S.B.; Connors, T.J.; Weisberg, S.P.; Krupska, I.; Matsumoto, R.; Poon, M.M.L.; Idzikowski, E.; et al. Longitudinal profiling of respiratory and systemic immune responses reveals myeloid cell-driven lung inflammation in severe COVID-19. Immunity 2021, 54, 797-814. [CrossRef] 
62. Abers, M.S.; Delmonte, O.M.; Ricotta, E.E.; Fintzi, J.; Fink, D.L.; de Jesus, A.A.A.; Zarember, K.A.; Alehashemi, S.; Oikonomou, V.; Desai, J.V.; et al. An immune-based biomarker signature is associated with mortality in COVID-19 patients. JCI Insight 2021, 6, e144455. [CrossRef]

63. Gomez-Rial, J.; Curras-Tuala, M.J.; Rivero-Calle, I.; Gomez-Carballa, A.; Cebey-Lopez, M.; Rodriguez-Tenreiro, C.; DacostaUrbieta, A.; Rivero-Velasco, C.; Rodriguez-Nunez, N.; Trastoy-Pena, R.; et al. Increased Serum Levels of sCD14 and sCD163 Indicate a Preponderant Role for Monocytes in COVID-19 Immunopathology. Front. Immunol. 2020, 11, 560381. [CrossRef] [PubMed]

64. Guetta, J.; Strauss, M.; Levy, N.S.; Fahoum, L.; Levy, A.P. Haptoglobin genotype modulates the balance of Th1/Th2 cytokines produced by macrophages exposed to free hemoglobin. Atherosclerosis 2007, 191, 48-53. [CrossRef] [PubMed]

65. Guest, C.B.; Park, M.J.; Johnson, D.R.; Freund, G.G. The implication of proinflammatory cytokines in type 2 diabetes. Front. Biosci. 2008, 13, 5187-5194. [CrossRef] [PubMed]

66. Collier, B.; Dossett, L.A.; May, A.K.; Diaz, J.J. Glucose control and the inflammatory response. Nutr. Clin. Pract. 2008, 23, 3-15. [CrossRef]

67. Esposito, K.; Nappo, F.; Marfella, R.; Giugliano, G.; Giugliano, F.; Ciotola, M.; Quagliaro, L.; Ceriello, A.; Giugliano, D. Inflammatory cytokine concentrations are acutely increased by hyperglycemia in humans: Role of oxidative stress. Circulation 2002, 106, 2067-2072. [CrossRef] [PubMed]

68. Pickup, J.C. Inflammation and activated innate immunity in the pathogenesis of type 2 diabetes. Diabetes Care 2004, 27, 813-823. [CrossRef]

69. Esser, N.; Legrand-Poels, S.; Piette, J.; Scheen, A.J.; Paquot, N. Inflammation as a link between obesity, metabolic syndrome and type 2 diabetes. Diabetes Res. Clin. Pract. 2014, 105, 141-150. [CrossRef]

70. Gresser, I.; Delers, F.; Tran Quangs, N.; Marion, S.; Engler, R.; Maury, C.; Soria, C.; Soria, J.; Fiers, W.; Tavernier, J. Tumor necrosis factor induces acute phase proteins in rats. J. Biol. Regul. Homeost. Agents 1987, 1, 173-176.

71. Stentz, F.B.; Umpierrez, G.E.; Cuervo, R.; Kitabchi, A.E. Proinflammatory cytokines, markers of cardiovascular risks, oxidative stress, and lipid peroxidation in patients with hyperglycemic crises. Diabetes 2004, 53, 2079-2086. [CrossRef]

72. Mirza, S.; Hossain, M.; Mathews, C.; Martinez, P.; Pino, P.; Gay, J.L.; Rentfro, A.; McCormick, J.B.; Fisher-Hoch, S.P. Type 2-diabetes is associated with elevated levels of TNF-alpha, IL-6 and adiponectin and low levels of leptin in a population of Mexican Americans: A cross-sectional study. Cytokine 2012, 57, 136-142. [CrossRef]

73. Castell, J.V.; Gomez-Lechon, M.J.; David, M.; Hirano, T.; Kishimoto, T.; Heinrich, P.C. Recombinant human interleukin-6 (IL-6/BSF-2/HSF) regulates the synthesis of acute phase proteins in human hepatocytes. FEBS Lett. 1988, 232, 347-350. [CrossRef]

74. Senn, J.J.; Klover, P.J.; Nowak, I.A.; Mooney, R.A. Interleukin-6 induces cellular insulin resistance in hepatocytes. Diabetes 2002, 51, 3391-3399. [CrossRef] [PubMed]

75. Feve, B.; Bastard, J.P. The role of interleukins in insulin resistance and type 2 diabetes mellitus. Nat. Rev. Endocrinol. 2009, 5 , 305-311. [CrossRef] [PubMed]

76. Maedler, K.; Dharmadhikari, G.; Schumann, D.M.; Storling, J. Interleukin-1 beta targeted therapy for type 2 diabetes. Expert Opin. Biol. Ther. 2009, 9, 1177-1188. [CrossRef]

77. Strandberg, L.; Lorentzon, M.; Hellqvist, A.; Nilsson, S.; Wallenius, V.; Ohlsson, C.; Jansson, J.O. Interleukin-1 system gene polymorphisms are associated with fat mass in young men. J. Clin. Endocrinol. Metab. 2006, 91, 2749-2754. [CrossRef]

78. Larsen, C.M.; Faulenbach, M.; Vaag, A.; Volund, A.; Ehses, J.A.; Seifert, B.; Mandrup-Poulsen, T.; Donath, M.Y. Interleukin-1receptor antagonist in type 2 diabetes mellitus. N. Engl. J. Med. 2007, 356, 1517-1526. [CrossRef]

79. Kzhyshkowska, J.; Gratchev, A.; Martens, J.H.; Pervushina, O.; Mamidi, S.; Johansson, S.; Schledzewski, K.; Hansen, B.; He, X.; Tang, J.; et al. Stabilin-1 localizes to endosomes and the trans-Golgi network in human macrophages and interacts with GGA adaptors. J. Leukoc. Biol. 2004, 76, 1151-1161. [CrossRef] 